\title{
MiR-192, miR-200c and miR-17 are fibroblast-mediated inhibitors of colorectal cancer invasion
}

\author{
Volker Ast ${ }^{1,2, *}$, Theresa Kordaß ${ }^{3, *}$, Marcus Oswald ${ }^{1,2}$, Amol Kolte ${ }^{1,2}$, David Eisel ${ }^{3}$, \\ Wolfram Osen ${ }^{3}$, Stefan B. Eichmüller ${ }^{3}$, Alexander Berndt ${ }^{4}$ and Rainer König ${ }^{1,2}$ \\ ${ }^{1}$ Integrated Research and Treatment Center, Center for Sepsis Control and Care, Jena University Hospital, 07747 Jena, \\ Germany \\ ${ }^{2}$ Network Modeling, Leibniz Institute for Natural Product Research and Infection Biology, Hans Knöll Institute Jena, 07745 \\ Jena, Germany \\ ${ }^{3}$ GMP \& T Cell Therapy Unit, German Cancer Research Center, 69120 Heidelberg, Germany \\ ${ }^{4}$ Institute of Forensic Medicine, Section Pathology, Jena University Hospital, 07747 Jena, Germany \\ * Shared first authors
}

Correspondence to: Rainer König, email: rainer.koenig@uni-jena.de

Keywords: mixed-integer linear programming; piecewise linear regression; extracellular matrix; tumor-associated fibroblast; tumor cell invasion

Received: April 20, $2018 \quad$ Accepted: October 06, $2018 \quad$ Published: October 30, 2018

Copyright: Ast et al. This is an open-access article distributed under the terms of the Creative Commons Attribution License 3.0 (CC BY 3.0), which permits unrestricted use, distribution, and reproduction in any medium, provided the original author and source are credited.

\section{ABSTRACT}

Colorectal cancer remains a leading cause of cancer-related death worldwide. A previous transcriptomics based study characterized molecular subgroups of which the stromal subgroup was associated with the worst clinical outcome. Micro-RNAs (miRNAs) are well-known regulators of gene expression and can follow a non-linear repression mechanism. We set up a model combining piecewise linear and linear regression and applied this combined regression model to a comprehensive colon adenocarcinoma dataset. We identified miRNAs involved in regulating characteristic gene sets, particularly extracellular matrix remodeling in the stromal subgroup. Comparison of expression data from separated (epithelial) cancer cells and stroma cells or fibroblasts associate these regulatory interactions with infiltrating stromal or tumor-associated fibroblasts. MiR-200c, miR-17 and miR-192 were identified as the most promising candidates regulating genes crucial for extracellular matrix remodeling. We validated our computational findings by in vitro assays. Enforced expression of either miR-200c, miR-17 or miR-192 in untransformed human colon fibroblasts down-regulated $85 \%$ of all predicted target genes. Expressing these miRNAs singly or in combination in human colon fibroblasts co-cultured with colon cancer cells considerably reduced cancer cell invasion validating these miRNAs as cancer cell infiltration suppressors in tumor associated fibroblasts.

\section{INTRODUCTION}

Colorectal cancer is a severe and lethal disease, accounting for almost $10 \%$ of all cancer-related deaths worldwide (in 2014, see [1]). The advent of deepsequencing technologies have provided valuable insight into the genomic and transcriptomic landscape of large colorectal sample cohorts [2], allowing the definition of distinct molecular subgroups [3]. However, to develop targeted, subgroup-specific treatment strategies, a mechanistic understanding of gene expression regulation is required. Since the discovery of microRNAs (miRNA), the knowledge and mechanistic understanding of gene regulation by miRNAs has expanded considerably. Several 
studies elucidated that miRNAs cause gene dysregulation and, by this, acting as tumor suppressors or oncomiRs [4]. Aberrantly expressed miRNAs have been shown to actively participate in tumor initiation, development, progression and invasion in multiple human cancer types [5], which makes them attractive targets for new therapeutic strategies. Particularly, miRNAs suit as prognostic markers and may serve as attractive candidates for targeted therapy of colorectal cancer [6]. Functional assays using miRNA transfection [7] and clinical trials show promising results to support miRNA-based treatment of specific cancer types, e.g. miR-34a targeting oncogenes and genes involved in tumor immune evasion [8]. Typically, miRNAs are expressed in a spatiotemporal-specific pattern. Their regulating effect depends on the cell type, tissue, RNAinduced silencing complex (RISC) availability, binding site abundance and seed sequence complementarity. It was observed that more abundant miRNAs can repress their targets to a higher degree [9]. However, luciferase target assays in Drosophila revealed that even miRNAs expressed at similar levels exhibited quite different repression effects [9]. In other studies, the authors investigated the repression of targets based on different miRNA dosages and concluded that only highly abundant miRNAs can effectively influence the expression of their target genes [10], suggesting a non-linear behavior. To address these observations of a threshold-dependent, non-linear regulation of target genes by miRNAs, we implemented a piecewise linear model to predict miRNA - target gene regulation using gene and miRNA expression profiles. This flexible approach approximates a non-linear behavior while still benefiting from the advantages of linear approaches such as robustness and low computation intensity. We explored miRNAs and their target gene regulation using a colon adenocarcinoma dataset [2] form The Cancer Genome Atlas (TCGA). We identified miR-192, miR-200c and miR-17 as regulators of genes involved in remodeling the extracellular matrix, in particular in the stromal subgroup of colorectal cancer. Observing transcription profiles of cancer samples sorted into stromal and tumor cells, we found this regulatory mechanism to happen in tumor-associated fibroblasts in the tumor microenvironment. This hypothesis was validated experimentally by (1) distinctive down-regulation of $85 \%$ of the predicted target genes after transfection of the identified miRNAs singly or in combination in fibroblasts, and (2) reduced invasion of colorectal cancer cells co-cultured with transfected fibroblasts employing Boyden-chamber assays.

\section{RESULTS}

\section{Predicting miRNA target genes with a combined regression model outperforms predictions of linear regression models}

To identify miRNA targets using miRNA and gene expression profiles from the same patients, typically, a linear regression model is set up which aims to estimate the expression of a certain target gene by the expression of one or multiple potential miRNAs taken from miRNA - target gene prediction tools or databases (see e.g. [11]). As stated above, gene regulation by miRNAs often shows a non-linear, threshold dependent behavior. Therefore, we extended the concept of linear regression models by implementing piecewise linear models (details of the mathematical realization are given in Supplementary 1.1). As a reference method, we established a standard linear regression model similar as in [12] (details, see Supplementary 1.2). We tested both methods on comprehensive sets of gene and miRNA expression profiles of two cancer entities taken from The Cancer Genome Atlas, i.e. of colon and prostate adenocarcinoma. The performance of our method (piecewise linear) and the standard method (linear regression) was evaluated by comparing the lists of predicted target genes with lists of genes being significantly down-regulated after transfection of the corresponding miRNAs in colon (or prostate) cancer cells. For this, we used publicly available miRNA transfection experiments (see Supplementary 1.3). In both datasets, the piecewise linear model outperformed the linear model in the majority of the transfection experiments, reflecting the non-linear gene regulation by miRNAs. Combining the results from both models considerably improved the target gene predictions (results in Supplementary 2.1, Supplementary 2.2 and Supplementary Table 7). In the following, we focus on the analysis of colon adenocarcinomas, and, due to its superiority, we use only the predictions from the combined regression model to identify target genes for miRNAs.

\section{The combined regression model identifies miRNAs and functional gene sets specific for molecular colorectal cancer subgroups}

By applying the combined regression model described above, we identified a total of 10,620 miRNA - target gene pairs predicted to be regulated by 310 different miRNAs. To identify functional processes regulated by a certain miRNA, we performed gene set enrichment analysis on the predicted target genes for each miRNA. Enriched gene sets were grouped into 18 broader categories (see Supplementary 1.4 for details). To further specify miRNAs and miRNA regulated processes, we investigated their potential regulation for molecular colorectal cancer subgroups defined by Guinney et al. [3]. We determined differentially expressed miRNAs and genes in each subgroup and selected miRNA - target gene pairs from the enriched gene sets with opposed expression (miRNA up-regulated and target genes down-regulated or vice versa), focusing on the mostly observed inhibitory effect of miRNAs. The workflow is depicted in Figure 1A.

In the MSI immune tumor subgroup, 6 of the predicted miRNAs were down-regulated and associated 
with 43 enriched, up-regulated gene sets. Among the down-regulated miRNAs, miR-335 and miR-362 were enriched in gene sets related to the immune system, including inflammatory response, adaptive immune response and T-cell differentiation. Only 2 up-regulated miRNAs (miR-155 and miR-223) were associated with
2 down-regulated gene sets (fatty acid oxidation and negative regulation of transcription from $R N A$ polymerase II promoter) in the MSI immune tumor subgroup. Supplementary Figure 2A-2B depicts these results and Supplementary Table 8 lists all of the identified gene sets, together with their categories. The canonical tumor

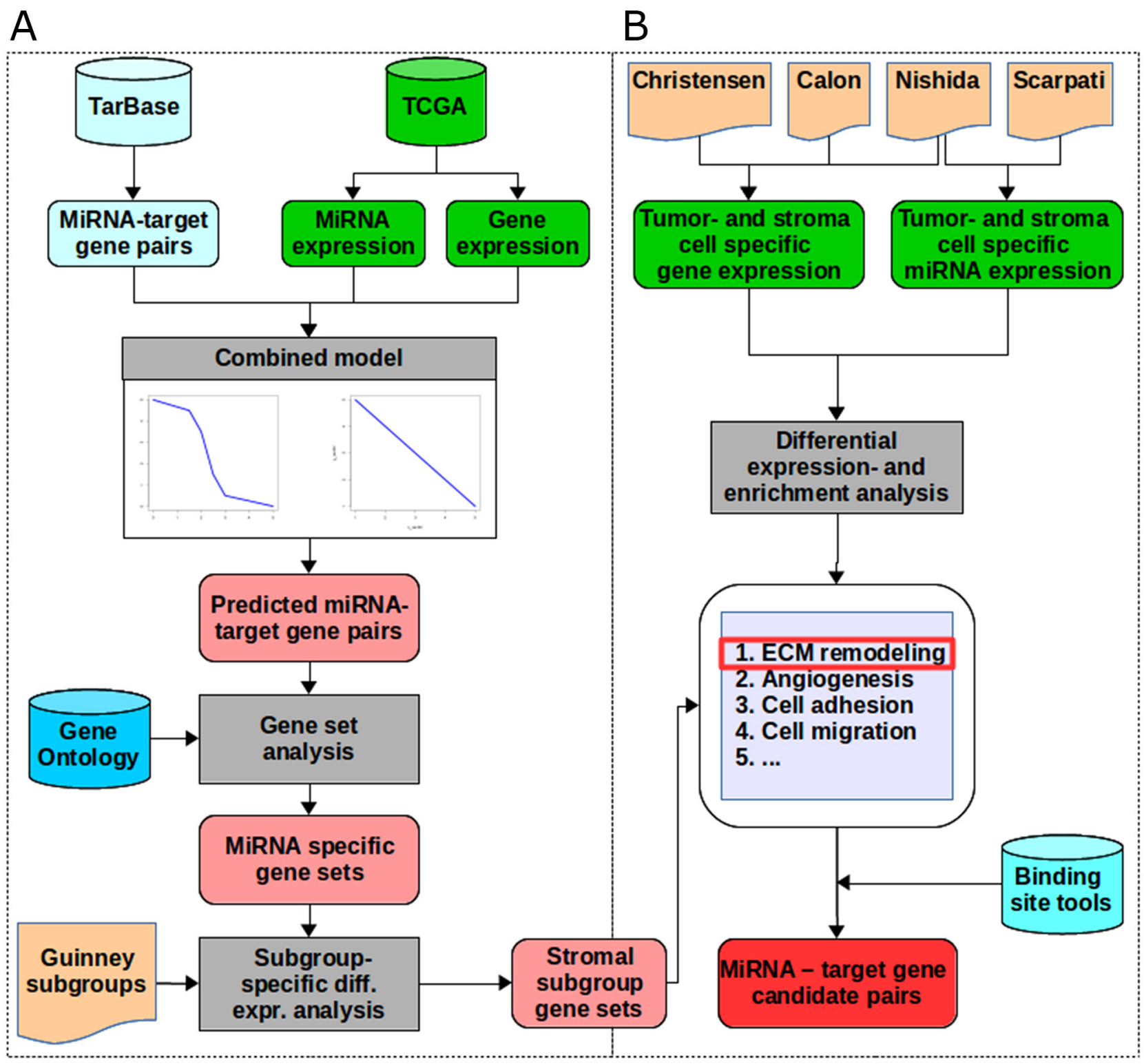

Figure 1: The workflow. (A) We extracted miRNA - target gene pairs from TarBase and miRNA- and gene expression data for a colon adenocarcinoma dataset from TCGA as input for the combined model consisting of the linear and the piecewise linear model. Out of these we selected all target genes with a good prediction performance. For each miRNA, we performed gene set enrichment analysis on the target genes predicted by the combined model using the gene set definitions from Gene Ontology. By integrating colorectal cancer subgroup definitions from Guinney et al., we tested for differential expression of miRNAs and genes of each subgroup versus all other subgroups. For each subgroup, we selected pairs with opposed expression direction (miRNA up-regulated and target genes down-regulated or vice versa). This resulted in subgroup-specific miRNAs and their enriched regulated gene sets. The stromal subgroup was selected for further analysis. (B) Among the enriched gene sets in the stromal subgroup we identified extracellular matrix remodeling (ECM) as the most prominent gene set. MiRNA and gene expression data of cells being sorted into tumor- and stroma origin were extracted from four different studies. Differential expression, enrichment analysis and integration of binding site predictions identified 39 miRNA - target gene pairs involved in ECM remodeling. 
subgroup had 28 up-regulated miRNAs which were associated with 169 enriched gene sets containing downregulated target genes (Supplementary Figure 2C-D and Supplementary Table 8). A member of the miR-17 92 cluster, miR-17, was up-regulated and associated with target genes in the functional gene sets apoptosis, cell differentiation, cell activation and angiogenesis. This is in line with Guinney et al. [3] who reported up-regulation of miR-17 and other miR-17 92 family members in the canonical tumor subgroup. In contrast to MSI immune subgroup tumors, miR-335 and miR-362 were upregulated and many of their target genes (miR-335: $\mathrm{n}=100$, miR-362: $\mathrm{n}=12$ ) encoding proteins involved in immune functions were down-regulated in the canonical tumor subgroup. Only two miRNAs (miR-615, miR-132) were down-regulated, corresponding with 5 enriched, up-regulated gene sets in canonical tumors. Although we identified 9 up-regulated miRNAs associated with 25 enriched gene sets in the metabolic tumor subgroup, only 2 gene sets, carbohydrate derivative biosynthetic process and positive regulation of cellular catabolic process, were associated with metabolism (Supplementary Figure 2E and Supplementary Table 8). From the 6 down-regulated miRNAs identified by Guinney et al. [3] our analysis only confirmed let-7e to be down-regulated in the metabolic tumor subgroup. However, GSEA analysis detected no enriched functional gene sets for the down-regulated miRNAs in this tumor subgroup. We identified the majority of differentially expressed miRNAs associated with functional gene sets in the stromal tumor subgroup. To note, as our data show the mesenchymal subgroup defined by Guinney et al. [3] to be enriched with tumorassociated stromal cells, we use the term "stromal subgroup". These gene sets included a total of 86 downregulated miRNAs that were associated with up-regulated target genes belonging to 289 enriched gene sets and 14 up-regulated miRNAs targeting down-regulated genes in 29 gene sets (Figure 2 and Supplementary Table 8). Target genes associated with cell cycle and DNA repair processes were down-regulated in stromal subgroup tumors and corresponded to 11 up-regulated miRNAs. We confirmed all 5 miRNAs (miR-141, miR-200a, miR-200b, miR200c and miR-429) determined to be down-regulated by Guinney et al. [3], and identified further down-regulated miRNAs as potential regulators of gene sets associated with angiogenesis, cell migration and endothelial and muscle cell differentiation, including miR-17 and members of the miR-29b, miR-16 and miR-7 families. The most prominently regulated functional gene sets in the stromal tumor subgroup were extracellular matrix organization (18 miRNAs, including miR-192 and miR200c, associated with 89 target genes) and extracellular matrix disassembly (5 miRNAs, including miR-17, associated with 19 target genes). Supplementary Table 9 summarizes miRNAs, target genes and their specific role concerning extracellular matrix synthesis, organization, maintenance and signaling. The functional grouping of the target genes is briefly described in Supplementary 1.5. The key process of extracellular matrix remodeling is central for tumor cell migration, invasion and metastasis and may at least partially underlie the poor clinical course of patients with stromal subgroup tumors. For this reason, we focused our further investigation on the regulatory role of miRNAs in extracellular matrix remodeling in the stromal subgroup tumors. Our approach using a combination of piecewise linear and linear model predicted miRNA target genes that could be linked to functional contexts and identified miRNAs as potential regulators of subgroupspecific gene sets in colorectal cancer.

\section{Tumor-associated fibroblasts substantially impact the phenotype of stromal subgroup tumors}

Extracellular matrix (ECM) remodeling is a hallmark of tumor infiltration and metastasis $[13,14]$. Compared to all other subgroups, stromal subgroup tumors were described by Guinney et al. as (i) more invasive, (ii) more metastatic, (iii) having reduced tumor cell content and (iv) being infiltrated by increased numbers of stromal cells (3). Isella et al. [15] and Calon et al. [16] also reported that a substantial fraction of transcriptomes from mesenchymal colorectal cancer subtypes could be explained by the stromal, rather than the epithelial tumor component. However, neither study mentioned the impact on ECM remodeling and its regulation by miRNAs. We investigated whether expression shifts in the miRNAs we identified and their corresponding ECM target genes (the combined 22 miRNAs and 91 target genes from the functional gene sets extracellular matrix organization and extracellular matrix disassembly) could be explained by stromal rather than tumor cells in samples of the stromal subgroup. We first assessed the differences of tumor and stromal cell proportions between samples of the stromal subgroup and the combination of samples of all other subgroups using image-based cell type estimates [2] (attribute details described in Supplementary 1.6). Stromal subgroup tumors contained $4.9 \%$ (bottom part of the image, $\mathrm{p}=0.013$ ) and $3.4 \%$ (top part of the image, $\mathrm{p}=0.031$ ) more stromal cells than the tumors from all other subgroups (Figure 3A-3B). In line, stromal subgroup samples contained $6.4 \%$ (bottom part of the image, $\mathrm{p}=0.0057$ ) and $8 \%$ (top part of the image, $\mathrm{p}=3.57 \mathrm{e}-5$ ) fewer tumor cells compared to samples from other subgroups (Figure 3C-3D). Stromal cells like fibroblasts, endothelial and immune cells can be adapted by the tumor to form a permissive tumor microenvironment supporting tumor protection, growth and invasion [17]. In response to cancer growth, quiescent fibroblasts residing in the stroma can be activated by growth factors such as TGF- $\beta$ to become tumor-associated fibroblasts [17]. Tumor-associated fibroblasts are considered to be the main producers of 
Angiogenesis Apoptosis Cell adhesion Cell cycle
Cell differentiation Cell migration Developmental process DNA repair
Gene set categroy

Extracellular matrix process Immune system process Localization/transport

Metabolic process
Nervous system process Translation

Receptor signaling Response to stimuli

Transcription

A

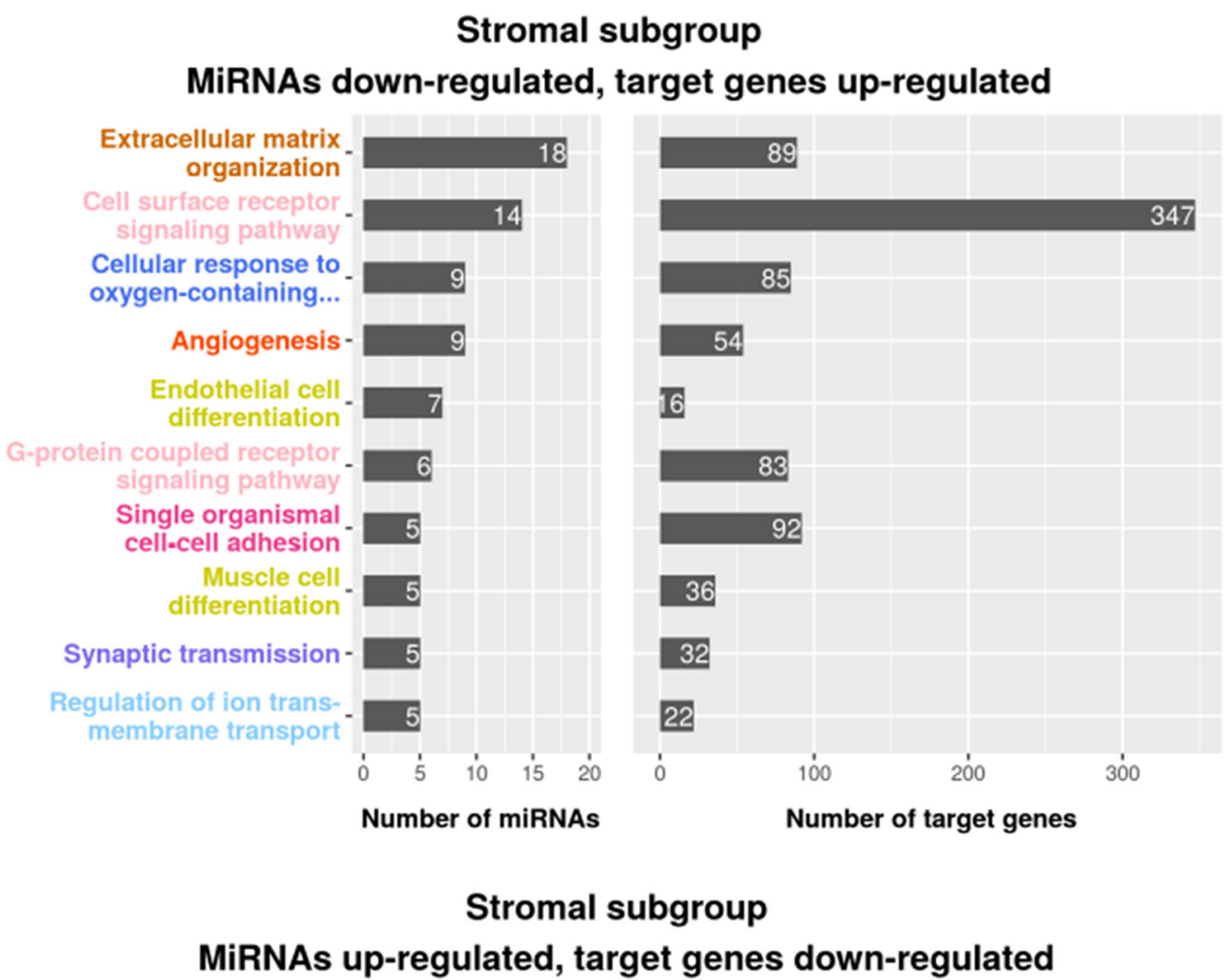

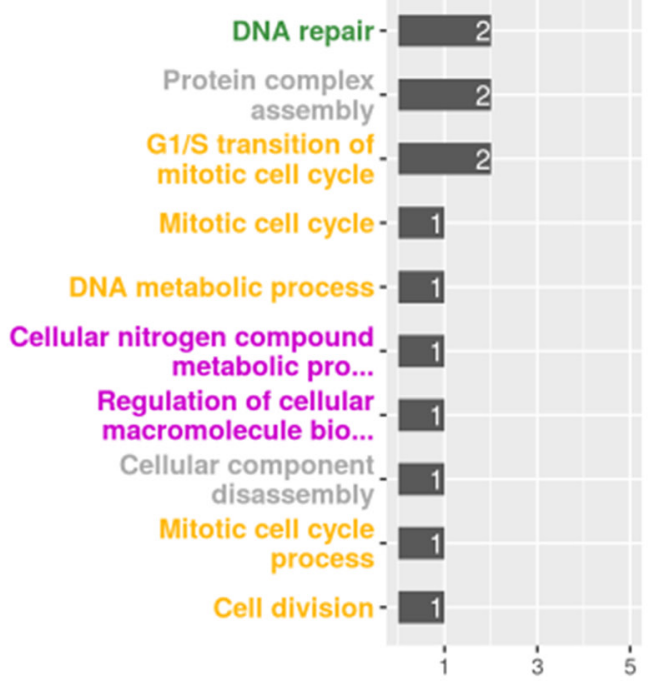

Number of miRNAs

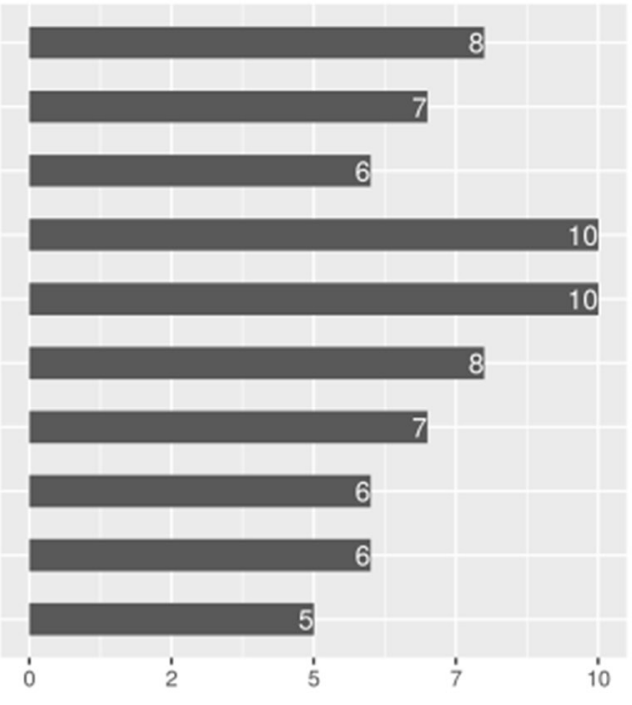

Number of target genes

Figure 2: Enriched gene sets of differentially expressed genes and miRNAs in the stromal subgroup. The top 10 gene sets are listed according to the number of regulating miRNAs (left) and the number of enriched target genes (right). The color indicates the assigned gene set category, (A) miRNAs down-regulated, target genes up-regulated, (B) miRNAs up-regulated, target genes downregulated. 
ECM components, related proteins and growth factors in the tumor stroma $[13,17]$. Similar to myofibroblasts in wounds or fibrotic tissues, tumor-associated fibroblasts are known to overexpress ACTA2, FAP and PDGFRB [18]. Indeed, ACTA2 ( $p=2.34 \mathrm{e}-32), \operatorname{FAP}(p=1.32 \mathrm{e}-11)$ and PDGFRB $(p=3.37 \mathrm{e}-21)$ expression were significantly upregulated in the stromal subgroup tumors (Supplementary Figure 3). In summary, the proportion of stromal cells was higher in samples of the stromal tumor subgroup compared to samples of other subgroups. We found an up-regulation of known marker genes for tumor-associated fibroblasts, suggesting an increased contribution of these cells to the transcriptomic profile of stromal subgroup tumors.

\section{MicroRNAs regulate ECM target genes in the tumor stromal component}

Our analysis identified 186 miRNA - target gene pairs containing 22 down-regulated miRNAs and 91 upregulated, ECM-related target genes in the stromal tumor subgroup (Supplementary Table 9). In the following, the list of 22 miRNAs and the list of 91 target genes will be referred to as candidate miRNAs and candidate target genes, respectively. We were interested if the candidate target genes were rather expressed in the tumor cells or in the cells of the tumor microenvironment. For this, we investigated expression profiles of tumors and their microenvironment, separated into tumor cells and fibroblasts ("Calon" [19] and "Christensen" [20] datasets, only gene expression) or stromal cells ("Nishida" dataset [21], gene and miRNA expression; Scarpati dataset [22], only miRNA expression). Differential expression analysis identified 17 genes in the dataset of Christensen et al. [20], 51 genes in the dataset of Calon et al. [19] and 70 genes in the dataset of Nishida et al. [21] to be up-regulated in tumor-associated fibroblasts or stroma cells (Supplementary Table 10A-10C). Intersecting the 91 candidate target genes with the three lists of upregulated genes in tumor-associated fibroblasts or stroma cells revealed significant enrichment in all three lists ( $p$ $<2 \mathrm{e}-5$ in each list). We did not find any of the candidate target genes to be up-regulated in tumor cells in the investigated three datasets. To refine our list, we selected those candidate target genes which were up-regulated in at least one of the three datasets, leading to a refined list of candidates of ECM related target genes $(n=76$, "refined candidate target genes"). Among these refined candidates were genes encoding for integral ECM components (collagen, laminin and fibulin) as well as matrix degrading enzymes (particularly matrix metallopeptidases), matrix synthesis proteins (members of the lysyl oxidase family such as LOXL2) and genes involved in ECM-cell signaling (integrin ITGB1 and growth factor FGF2). To investigate the expression of the 22 candidate miRNAs in tumor and stromal cells, we analyzed their expression profiles in the datasets from Nishida and Scarpati. We confirmed that miR-192 and miR-17 were down-regulated in the stromal component compared to cancer cells, as reported by Nishida et al. [21] (Supplementary Table 11A) and that miR-17, miR-192 and miR-200c were downregulated in stroma cells, as reported by Scarpati et al. [22] (Supplementary Table 11B). We performed gene set enrichment analysis on the 22 miRNAs among all downregulated miRNAs in stromal cells in the Nishida dataset and observed a significant enrichment $(p<2 e-5)$. These 22 candidate miRNAs were not significantly enriched among all down-regulated miRNAs in stromal cells in the Scarpati dataset $(p=0.18)$, however, a tendency towards enrichment was observed. None of the 22 candidate miRNAs were up-regulated in stromal cells in either dataset. As refined candidate miRNAs, we selected miR192 and miR-17, which were significantly down-regulated in stromal cells in both datasets, and miR-200c, which was among the top 5 miRNA with the strongest downregulation in stromal cells in the Scarpati dataset. Filtering the initial 186 miRNA - target gene pairs using the lists of refined candidate target genes and refined candidate miRNAs yielded 20 pairs with miRNAs that were downregulated and target genes that were up-regulated in tumor-associated fibroblast or stromal cells respective. By integrating binding site predictions of miRNA - ECM target gene combinations that were not predicted by our combined model, we could specify 19 additional miRNA - target gene pairs and extended our result set to overall 39 candidate pairs. We identified SPARC, FGF2, DST, PLOD1, LOXL2, ITGB1, ITGAV, PXDN, FBN1, FN1, KDR, MMP2 and TGFB1 as potential target genes of miR-192; MMP2, FSCN1, LAMC1, TGFB1, DST, ETS1, FBN1, FGF2, FN1, ITGAV, ITGB1, PXDN and TIMP2 as feasible miR-17 targets; and ETS1, KDR, SERPINH1, TIMP2, NCAM1, FN1, FBLN5, DST, FGF2, ITGAV, ITGB1, PLOD1 and SPARC as potential miR-200c target genes (Table 1).

Taken together, our re-analysis of 4 datasets separating expression from the stromal and tumor cell components of colorectal cancers have paired overexpressed target genes responsible for ECM (dis)assembly and regulation with the down-regulation of miR-192, miR17 and miR-200c in tumor-associated fibroblasts. This gene regulatory network may be pivotally involved in ECM remodeling in the stromal colorectal tumor subgroup and might be highly relevant for colorectal cancer cell invasion and metastasis.

\section{Enforced expression of miR-192, miR-17 and miR-200c in fibroblasts suppresses predicted target gene expression in vitro}

We set out to experimentally validate our computationally derived hypothesis involving the 
miRNAs and ECM-remodeling target genes identified. We tested the suppressive effect of miR-192, miR-17 and miR-200c on their respective target genes by transfecting

A

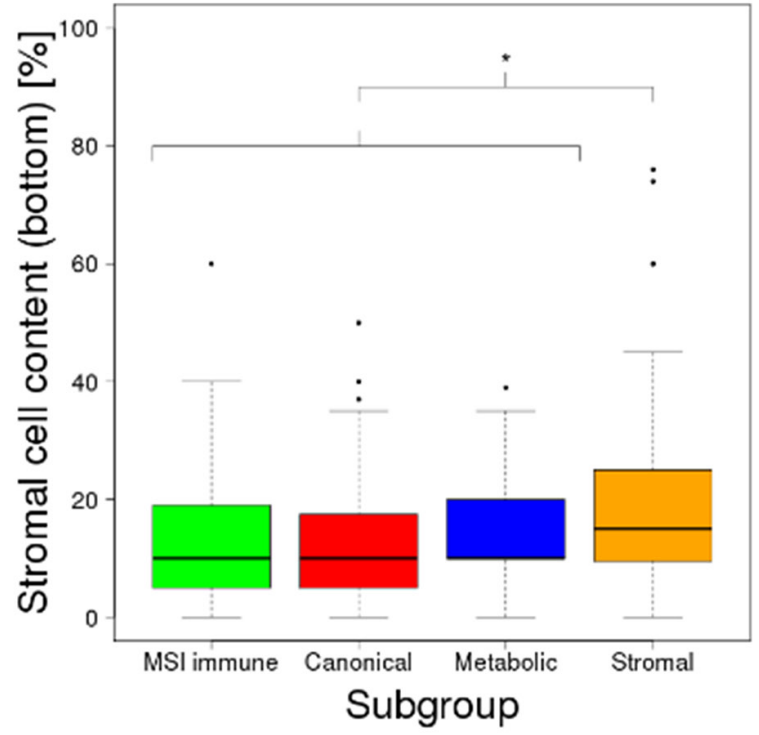

C

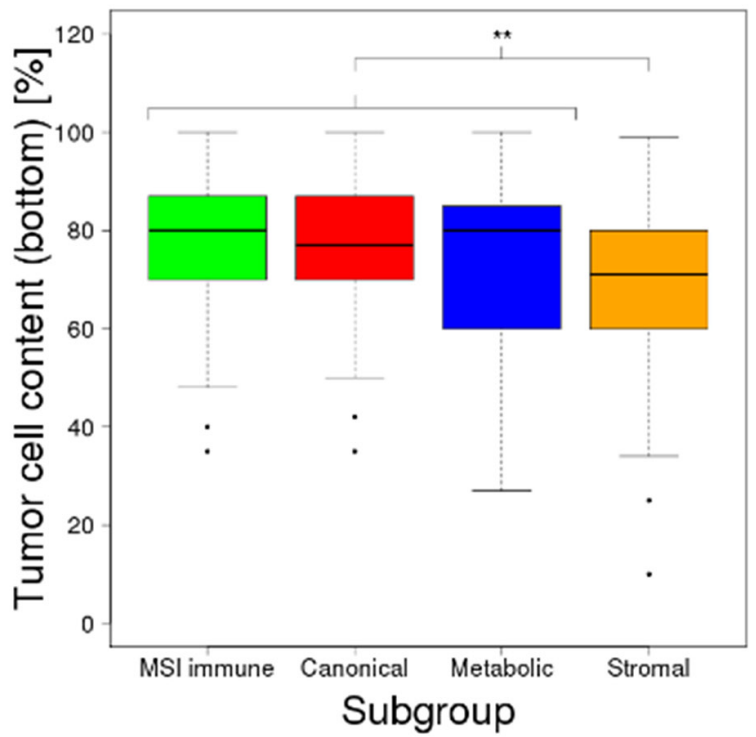

miRNA mimics or a control mimic into human fibroblasts and subsequently assessed target gene expression using qPCR. ITGAV, ITGB1, LOXL2, PLOD1, FGF2, FN1 and

B

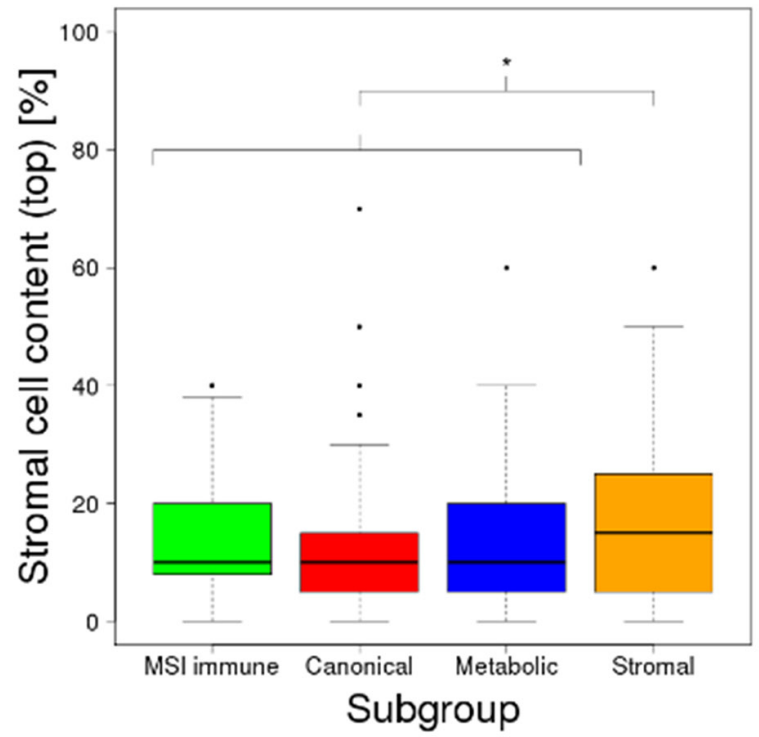

D

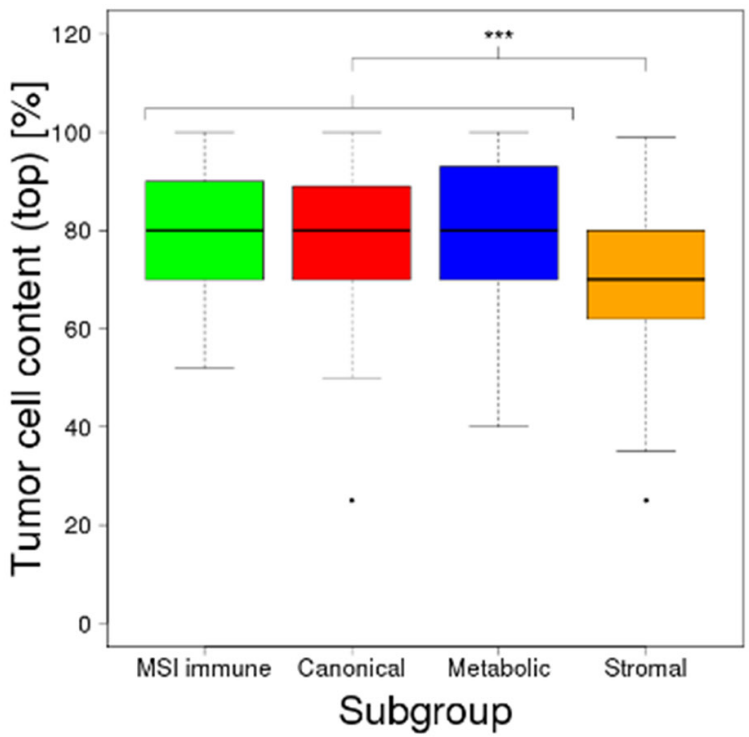

Figure 3: Estimated percentages of the content of stroma and tumor cells across the molecular subgroups. Estimated percentages of stroma cell content at (A) the bottom of the tissue slide image and (B) the top of the tissue slide image; estimated percentages of tumor cell content at (C) the bottom of the tissue slide image and (D) the top of the tissue slide image. The content of stromal cells was significantly higher (bottom: $\mathrm{p}=0.013$, top: $\mathrm{p}=0.031$ ) whereas the content of tumor cells was significantly lower (bottom: $\mathrm{p}=0.0057$, top: $\mathrm{p}=3.57 \mathrm{e}-5)$ in the stromal subgroup. The significance levels $\left({ }^{*}\right),\left(^{* *}\right)$ and $\left(^{* * *}\right)$ represent $\mathrm{p}$-values between 0.05 and 0.01 , between 0.01 and 0.001 and below 0.001 respectively. 
Table 1: Refined list of predicted candidate pairs of miRNAs and their target genes potentially involved in ECM remodeling

\begin{tabular}{|c|c|c|c|}
\hline MiRNA & Gene symbol & Gene name & Identification method \\
\hline hsa-mir-192 & FGF2 & Fibroblast Growth Factor 2 & Combined Model \\
\hline hsa-mir-192 & ITGAV & integrin subunit alpha $\mathrm{V}$ & Combined Model \\
\hline hsa-mir-192 & LOXL2 & lysyl oxidase-like 2 & Combined Model \\
\hline hsa-mir-192 & ITGB1 & integrin subunit beta 1 & Combined Model \\
\hline hsa-mir-192 & PLOD1 & $\begin{array}{c}\text { procollagen-lysine, } 2 \text {-oxoglutarate } \\
\text { 5-dioxygenase } 1\end{array}$ & Combined Model \\
\hline hsa-mir-192 & PXDN & peroxidasin & Combined Model \\
\hline hsa-mir-192 & SPARC & $\begin{array}{l}\text { Secreted Protein Acidic And } \\
\text { Cysteine Rich }\end{array}$ & Combined Model \\
\hline hsa-mir-192 & DST & Dystonin & Combined Model \\
\hline hsa-mir-192 & FBN1 & Fibrillin 1 & Combined Model \\
\hline hsa-mir-192 & FN1 & Fibronectin 1 & Binding site analysis \\
\hline hsa-mir-192 & KDR & Kinase Insert Domain Receptor & Binding site analysis \\
\hline hsa-mir-192 & MMP2 & Matrix Metallopeptidase 2 & Binding site analysis \\
\hline hsa-mir-192 & TGFB1 & Transforming Growth Factor Beta 1 & Binding site analysis \\
\hline hsa-mir-200c & ETS1 & ETS Proto-Oncogene 1 & Combined Model \\
\hline hsa-mir-200c & KDR & Kinase Insert Domain Receptor & Combined Model \\
\hline hsa-mir-200c & SERPINH1 & Serpin Family H Member 1 & Combined Model \\
\hline hsa-mir-200c & TIMP2 & TIMP Metallopeptidase Inhibitor 2 & Combined Model \\
\hline hsa-mir-200c & NCAM1 & Neural Cell Adhesion Molecule 1 & Combined Model \\
\hline hsa-mir-200c & FN1 & Fibronectin 1 & Combined Model \\
\hline hsa-mir-200c & FBLN5 & Fibulin 5 & Combined Model \\
\hline hsa-mir-200c & DST & Dystonin & Binding site analysis \\
\hline hsa-mir-200c & FGF2 & Fibroblast Growth Factor 2 & Binding site analysis \\
\hline hsa-mir-200c & ITGAV & integrin subunit alpha $\mathrm{V}$ & Binding site analysis \\
\hline hsa-mir-200c & ITGB1 & integrin subunit beta 1 & Binding site analysis \\
\hline hsa-mir-200c & PLOD1 & $\begin{array}{c}\text { procollagen-lysine, 2-oxoglutarate } \\
\text { 5-dioxygenase } 1\end{array}$ & Binding site analysis \\
\hline hsa-mir-200c & SPARC & $\begin{array}{l}\text { Secreted Protein Acidic And } \\
\text { Cysteine Rich }\end{array}$ & Binding site analysis \\
\hline hsa-mir-17 & MMP2 & Matrix Metallopeptidase 2 & Combined Model \\
\hline hsa-mir-17 & FSCN1 & Fascin Actin-Bundling Protein 1 & Combined Model \\
\hline hsa-mir-17 & LAMC1 & Laminin Subunit Gamma 1 & Combined Model \\
\hline hsa-mir-17 & TGFB1 & Transforming Growth Factor Beta 1 & Combined Model \\
\hline hsa-mir-17 & DST & Dystonin & Binding site analysis \\
\hline hsa-mir-17 & ETS1 & ETS Proto-Oncogene 1 & Binding site analysis \\
\hline
\end{tabular}

(Continued) 


\begin{tabular}{lccc}
\hline MiRNA & Gene symbol & Gene name & Identification method \\
\hline hsa-mir-17 & FBN1 & Fibrillin 1 & Binding site analysis \\
hsa-mir-17 & FGF2 & Fibroblast Growth Factor 2 & Binding site analysis \\
hsa-mir-17 & FN1 & Fibronectin 1 & Binding site analysis \\
hsa-mir-17 & ITGAV & integrin subunit alpha V & Binding site analysis \\
hsa-mir-17 & ITGB1 & integrin subunit beta 1 & Binding site analysis \\
hsa-mir-17 & PXDN & peroxidasin & Binding site analysis \\
hsa-mir-17 & TIMP2 & TIMP Metallopeptidase Inhibitor 2 & Binding site analysis \\
\hline
\end{tabular}

KDR were all down-regulated by enforced expression of miR-192. We observed a negative, yet not significant effect on the expression of SPARC, DST, PXDN and TGFB1. Surprisingly, miR-192 had a positive effect on the expression of MMP2 (Figure 4A and Supplementary Table 12A). The expression of FBN1 was below the detection level. TGFB1, LAMC1, MMP2, ITGAV, PXDN, FN1, TIMP2, FGF2, ITGB1 and DST were down-regulated after enforced expression of miR-17. We observed a positive effect on FBN1 and only very little effect on FSCN1 and ETS1 expression (Figure 4B and Supplementary Table 12B). Enforcing miR-200c expression caused downregulation of FN1, FBLN5, ETS1, TIMP2, SERPINH1, FGF2, PLOD1, NCAM1 and DST. The expression of ITGAV, ITGB1 and SPARC were also down-modulated by miR-200c, but were below the threshold. KDR showed a slightly positive alteration (Figure 4C and Supplementary Table 12C). In summary, we could validate $67 \%$ of our computationally predicted miRNA - target gene pairs by cell culture experiments. $85 \%$ of our 20 ECM candidate genes are targeted by at least one of the three candidate miRNAs. Remarkably, FGF2 and FN1 are down-regulated by all three miRNAs. We present $17 \mathrm{miRNA}$-regulated genes expressed in the stromal component of colorectal cancers and involved in ECM remodeling as potentially important in tumorigenesis.

\section{MiRNAs miR-192, miR-17 and miR-200c regulate ECM target genes on the protein level}

We investigated the effect of miR-192, miR-17 and miR-200c on the protein expression of their individual targets to elucidate if the miRNAs regulate ECM remodeling also on the protein level. We tested 28 miRNA - target gene pairs where the data was available for inverse correlation of miRNA expression and protein abundance (see Supplementary 1.7 for details). We observed significant negative correlation for 10 pairs: miR-200c and FN1 ( $p=2.94 \mathrm{e}-4)$, miR-17 and ITGAV ( $p=5.08 \mathrm{e}-4)$, miR-17 and FBN1 ( $\mathrm{p}=1.26 \mathrm{e}-3)$ miR-17 and FSCN1 $(p=3.74 \mathrm{e}-3)$, miR-17 and ITGB1 $(\mathrm{p}=4.17 \mathrm{e}-3)$, miR-17 and LAMC1 ( $p=7.86 \mathrm{e}-3), \operatorname{miR}-200 \mathrm{c}$ and ITGAV $(\mathrm{p}=9.03 \mathrm{e}-3)$, miR-200c and ITGB1 ( $p=1.26 \mathrm{e}-2), \mathrm{miR}-17$ and MMP2 $(p=2.6 e-2)$, and miR-192 and $\operatorname{SPARC}(p=4.93 e-2)$. A tendency of negative correlation was observed for miR-200c and SERPINH1 ( $p=5.49 \mathrm{e}-2), \mathrm{miR}-192$ and FN1 $(p=5.56 \mathrm{e}-2)$ and miR-192 and MMP2 $(\mathrm{p}=5.86 \mathrm{e}-2)$ (Supplementary Table 13). Afterwards, we compared the correlation coefficients of the 28 miRNA - target gene pairs with the correlation coefficients of all possible combinations of all other non-candidate miRNAs and proteins $(n=2,987,138)$ and observed a significant lower correlation of our candidate pairs $(p=3.68 \mathrm{e}-6$, Student's $t$-test). These results demonstrate that miR-192, miR-200c and miR-17 are not only inversely correlated to their ECM target genes but also to their expressed proteins.

As MMP2 is known to be a substantial player in ECM remodeling and associated with tumorigenesis [23], we measured the protein level of MMP2 in the supernatant of miRNA - transfected MRC5 and CCD-18Co fibroblasts using western blots to confirm our computational findings. We observed a reduced relative abundance of MMP2 in both cell lines after transfection with miR-200c, miR17 or miR-192 compared to a control transfection (see Supplementary Figure 4). The results in both cell lines indicate that the protein abundance of MMP2 is negatively affected by the identified miRNAs.

\section{Enforced miR-192, miR-17 and/or miR-200c expression in colon fibroblasts reduces invasive capacity of co-cultured colorectal cancer cells}

The question remains whether the miRNAmediated down-regulation of the 17 target genes in tumor-associated fibroblasts could affect the invasive capacity of the adjacent cancer cells. To experimentally test our hypothesis, we set up a Boyden-chamber assay with HCT-116 colon cancer cells in the inner chambers and CCD-18Co colon fibroblasts in the outer chambers and measured cancer cell invasion as mean fluorescent intensity. Fibroblasts were selectively transfected with mimics of miR-192, miR-17, miR-200c, a combination of all three mimics or a mock control mimic. HCT-116 cell invasion was significantly reduced by co-culture with colon fibroblasts expressing miR-200c $(p=7.5 e-3)$, miR-192 ( $\mathrm{p}=4.99 \mathrm{e}-3)$, miR-17 $(1.66 \mathrm{e}-2)$ or all 3 miRNA 


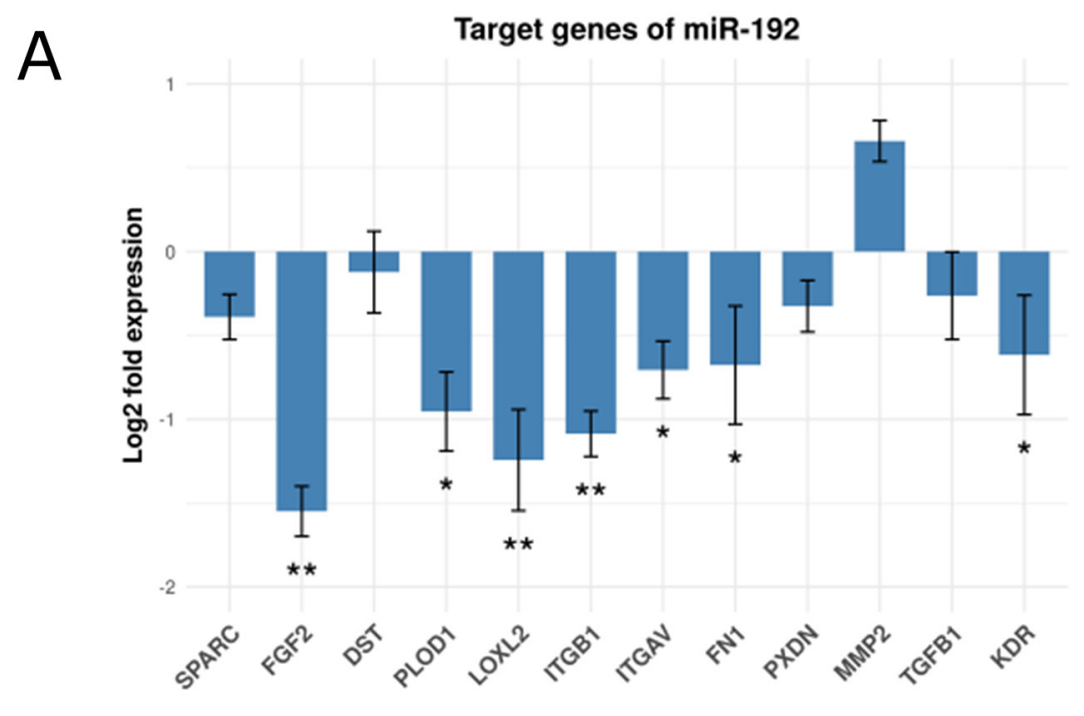

B

Target genes of miR-17

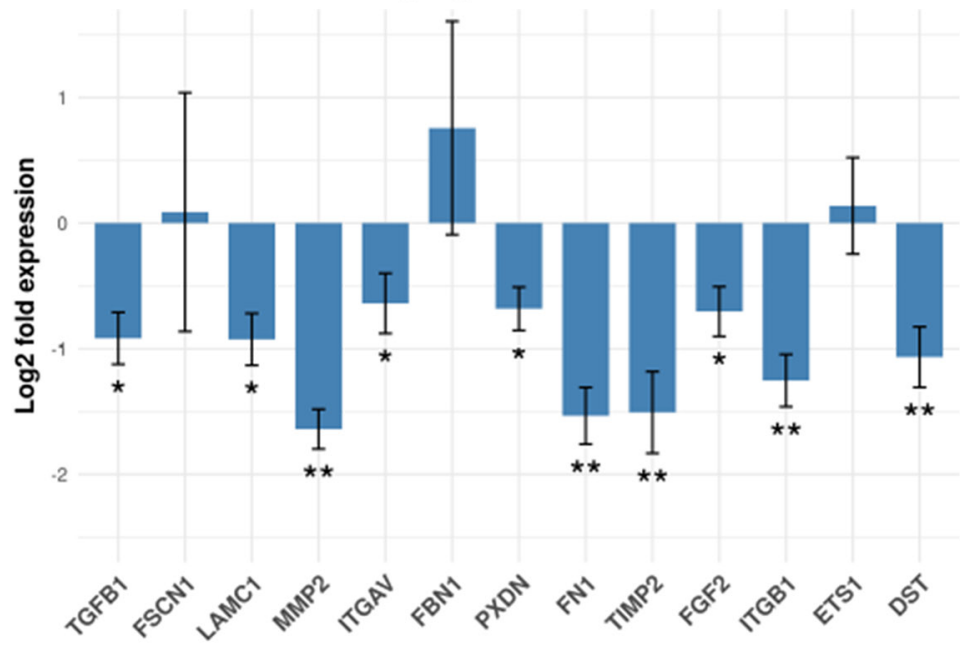

C

Target genes of miR-200c

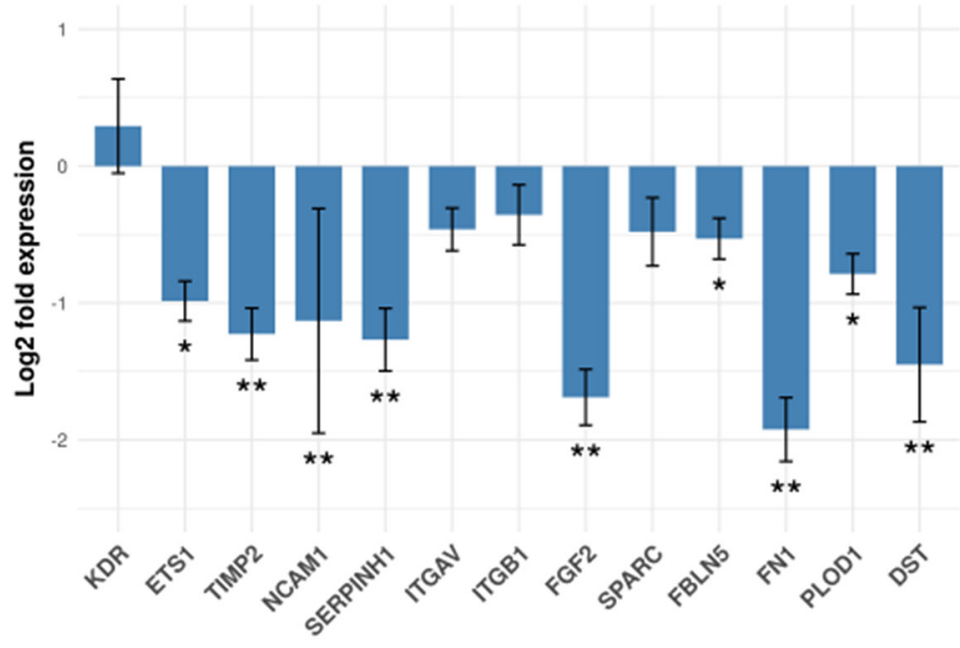

Figure 4: Fold change expression of the candidate genes after miRNA transfection in fibroblasts. Shown are bar-plots of ( $\log 2$ transformed) fold expression values (miRNA transfected versus miRNA controls), (A) Target genes of mir-192, (B) Target genes of mir-17 and (C) Target genes of mir-200c. $\left(^{*}\right)$ and $\left(^{* *}\right)$ represent $\log 2$ fold changes between -0.5 and -1 and between -1 and -2 respective. All experiments were performed in three $(\mathrm{n}=3)$ technical replicates. 
$(\mathrm{p}=2.7 \mathrm{e}-3$, Figure $5 \mathrm{~A})$. Enforced expression of either miR-192 $(\mathrm{p}=0.01)$ or miR-17 $(\mathrm{p}=0.04)$ also significantly reduced the invasive activity of CCD-18Co fibroblasts. This observation suggests that ECM remodeling initiated by miRNA regulation may affect both stromal and epithelial colorectal tumor components in vivo. Enforced expression of miR-200c alone $(\mathrm{p}=0.07)$ or the combination of all 3 miRNAs $(p=0.052)$ did not significantly impact the invasive activity of CCD-18Co fibroblasts, although we observed the same tendency towards reduced invasion (Figure 5B). To exclude any side effects of proliferation on the invasion of co-cultured cancer cells, we performed XTT proliferation assays. HCT-116 cells co-cultured with the supernatant of CCD-18Co fibroblasts that were transfected with miR-17, miR-200c or miR-192 beforehand showed no significant alteration of proliferation compared to a control transfection (Supplementary Figure 5). Further investigations using sophisticated 3D or in vivo tumor models are needed to show if the concept of migratory track preparation by tumor-associated fibroblasts proves relevant also for colorectal cancers, but are beyond the scope of this study. Our experimental data show that miR-192, miR-17 and miR-200c expression in fibroblasts impacts the migratory capacity of co-cultured colon tumor cells, strengthening the computationally predicted functional association with the increased metastatic quality of cancers of the stromal subgroup.

\section{DISCUSSION}

We established a piecewise linear model to observe non-linear regulation of gene expression by miRNAs. The method is implemented as an R (https://www.r-project.org/) package named MiRNA-RIP and is freely available at http://www.leibniz-hki.de/en/mirnarip.html. By including molecular subgroups of colorectal cancer established by Guinney et al. [3] in our analysis, we elaborated subgroupspecific miRNAs, their corresponding target genes and regulated functional gene sets. We identified miR-192, miR-17 and miR-200c as regulators of genes involved in extracellular matrix remodeling in the stromal subgroup of colon cancer.

\section{MiRNAs regulate ECM remodeling in the tumor microenvironment}

Most research on miRNAs in cancer to date focus on their specific roles in the cancer cells. A literature analysis revealed several colorectal cancer studies investigating the transcriptional discrepancy between cancer cells and their surrounding stromal cells [15-17]. We confirmed from publicly available imaging data that the molecularly defined stromal colorectal cancer subgroup had significantly increased proportions of infiltrated stromal cells. Hence, it was quite likely that the infiltrating stromal cells, or particularly tumor-associated fibroblasts, could explain the distinct gene expression pattern in this subgroup. We investigated data from several published miRNA and mRNA transcriptome studies of sorted stromal and cancer cells from colon tumors [19-22], and validated the hypothesis that up-regulated genes associated with ECM remodeling are more strongly expressed in the stromal rather than epithelial cancer cell component of tumors. In line with this, we identified their putative miRNA regulators to be significantly down-regulated in stromal cells. We experimentally validated these computational findings and observed down-regulation of $85 \%$ of the predicted ECM remodeling target genes in fibroblasts after enforced expression of miR-192, miR17 or miR-200c. Enforced expression of these miRNA regulators in fibroblasts also repressed invasive activity of co-cultured colorectal cancer cells. We argue that the three identified miRNAs down-regulate target genes associated with ECM remodeling in fibroblasts, and the downregulation of these miRNA regulators in stromal subgroup colorectal tumors could account for the heightened invasive or metastatic capacity of their cancer cells, sketched in Figure 6. Interestingly, we also observed a reduction of fibroblast migration after enforced expression of miR-192 or miR-17. This is in line with observations by Gaggioli et al. that squamous cell carcinoma cells migrate within tracks through the extracellular matrix behind tumor-associated fibroblasts [24] and similarly by Li et al. that adenoid cystic carcinoma cells follow the track behind tumor-associated fibroblasts [25]. This aspect could be another, indirect contribution of tumor-associated fibroblasts to tumor cell migration.

\section{Tumor-suppressive miR-192, miR-17 and miR- $200 \mathrm{c}$ are known regulators in cancer}

Some evidence that miR-192, miR-17 and miR-200c play a role in cancer pathophysiology has been described in the literature. Geng et al. [26] reported that miR-192 expression progressively decreased with increasing colorectal cancer stage, being lowest in stage IV tumors, and demonstrated in mouse models that enforced expression of miR-192 inhibits metastatic colonization of the liver. In medulloblastoma, miR-192 has been described as a suppressor of metastasis and inhibitor of cell adhesion to ECM components via integrins such as ITGB1 and ITGAV [27]. MiR-200c is a regulator of epithelial-tomesenchymal transition which targets the transcriptional repressors of E-cadherin, ZEB1 and ZEB2 [28], suggesting a tumor suppressive function. The miR-200c - ZEB1 axis was also linked to invasive activity in breast cancer cells [29]. Hur et al. [30] compared miR-200c expression in primary colorectal tumors, and reported that lower miR$200 \mathrm{c}$ expression correlated with increased metastatic activity. They used in situ hybridization to show that miR$200 \mathrm{c}$ expression gradually decreased from the lumen to the 
submucosa in primary colorectal tumors, contributing to a higher metastatic potential at the invasive tumor front [30]. Chen et al. [31] associated elevated miR-200c expression in colon cancer cells with lymph node metastasis, invasion and resistance to cytarabine treatment. The genomic locus of the miR-17 92 cluster is a direct target of the MYC family oncogenes. The locus has been shown to be amplified in tumor cells and its overexpression has been associated with tumor-promoting processes in several malignancies (reviewed in [32]). Despite its known tumorpromoting abilities, the expression of the miR-17 92 cluster in prostate cancer cells has been shown to inhibit cell migration and epithelial-to-mesenchymal transition, suggesting a tumor suppressive role in some cases [33]. Expression of miR-17 in colorectal tumors has been reported to increase with cancer severity, from adenoma to adenocarcinoma [34]. Strikingly, expression was confined to the epithelial cancer cell component of these tumors. These studies do not contradict our observations, since we detect the miRNA down-regulation specifically in the tumor-associated stromal cells, and, in relation to the stroma, expression in the epithelial tumor cells. As a future aspect, it would be intriguing to investigate the expression of miR-17 and miR-200c in the surrounding stroma of the
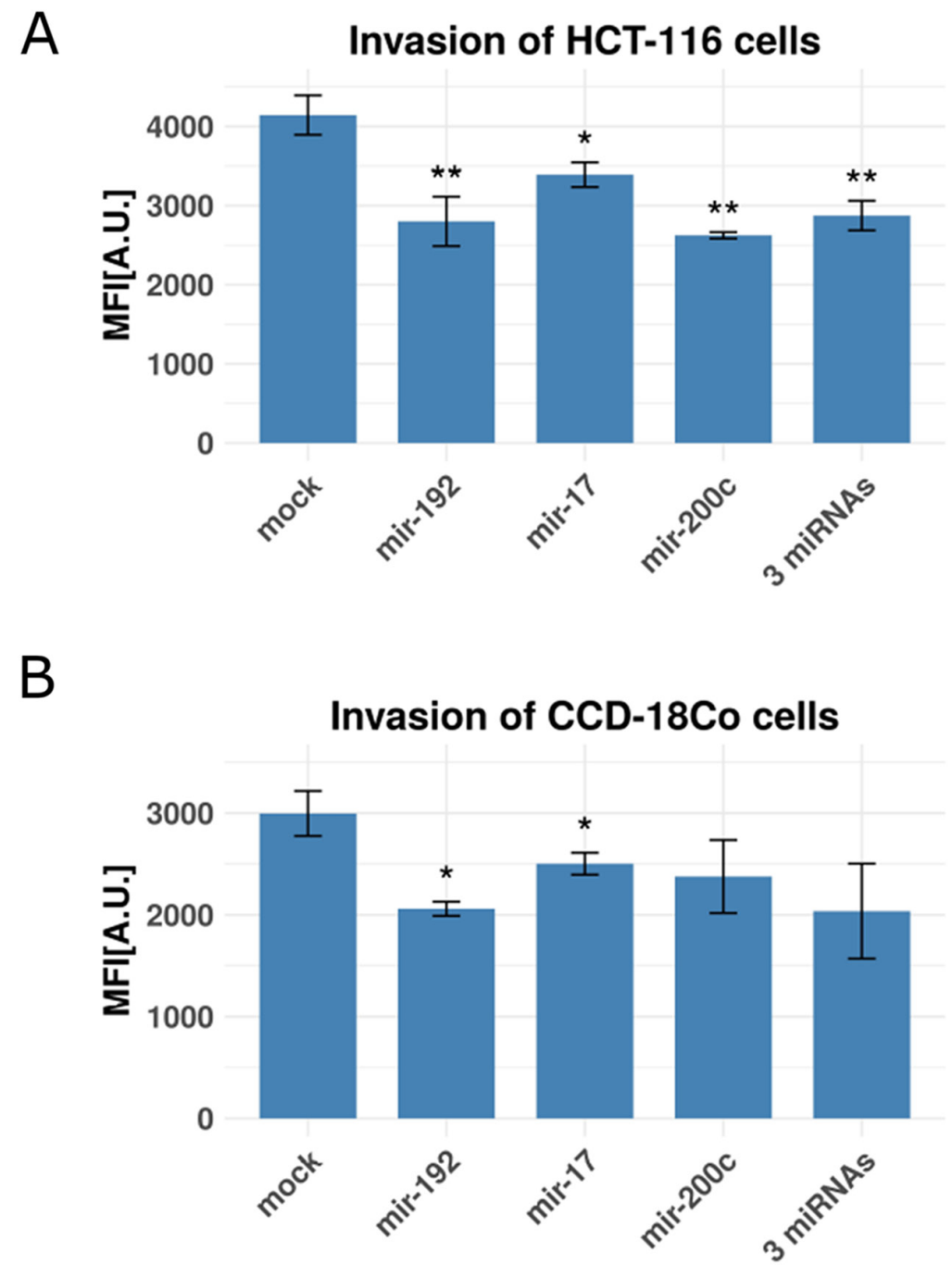

Figure 5: Invasion rates of colon cancer cells and fibroblasts with and without miRNA transfection. Shown are bar plots of invasion rates as relative mean fluorescence intensities (MFI) in arbitrary units [A.U.]. (A) Co-cultured HCT-116 cancer cells and CCD$18 \mathrm{Co}$ fibroblasts (with CCD-18Co cells in the lower chamber) transfected with mir-192, mir-17, mir-200c and a combination of all three miRNAs using a mock-transfection as control. (B) CCD-18Co fibroblasts, transfected with mir-192, mir-17, mir-200c and a combination of all three miRNAs using a mock-transfection as control. $\left({ }^{*}\right),\left({ }^{* *}\right)$ and $\left({ }^{* * *}\right)$ represent p-values between 0.05 and 0.01 , between 0.01 and 0.001 and below 0.001 respective. All experiments were performed in three $(n=3)$ technical replicates. 
reported tumor types, and in particular for tumors with amplification or overexpression of the MYC oncogene family.

\section{ECM remodeling genes contribute actively to tumor invasion}

The identified target genes have been reported in the literature in the context of invasion and metastasis. LOXL2 is a member of the lysyl oxidase gene family which catalyzes the crosslinking of extracellular collagen and elastin resulting in increased ECM stiffness and subsequent activation of the kinases FAK and SRC, which enable tumor cells to proliferate and invade. Furthermore, LOXL2 is involved in metastasis [35-37]. LOXL2 expression is increased in a number of tumor types, including colorectal cancer [38] where it is also a marker
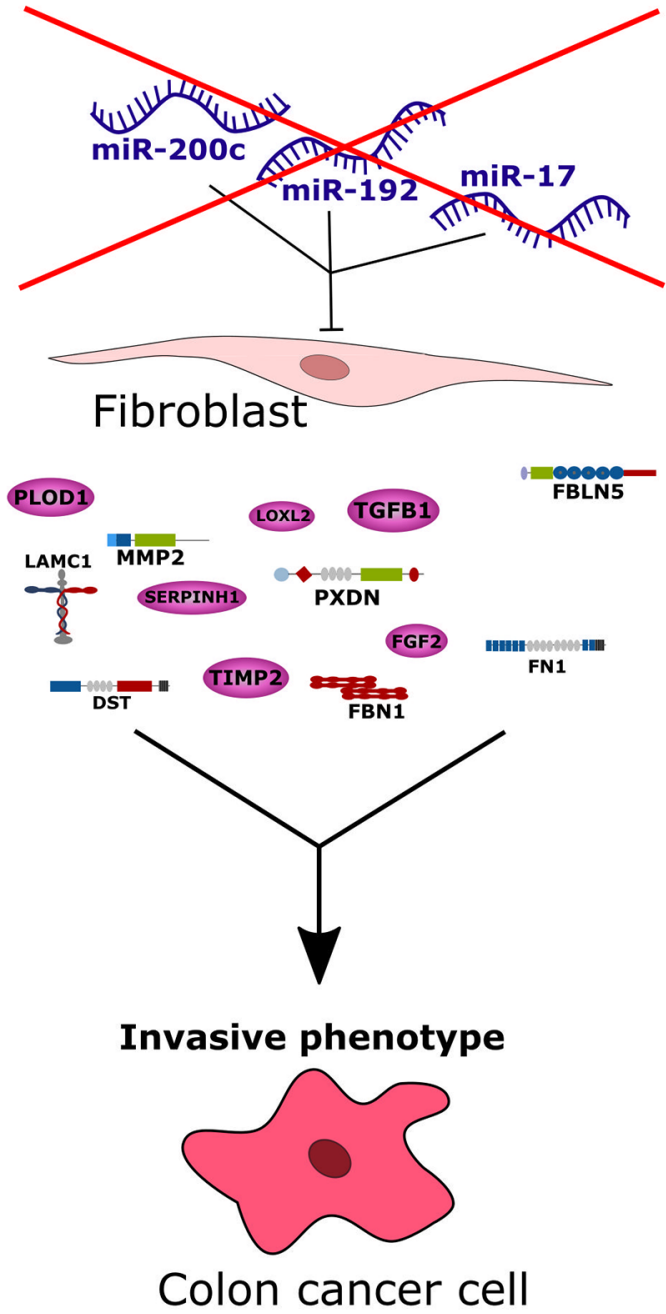

for poor prognosis [37]. Specific knockdown experiments demonstrated a stimulating role of LOXL2 during cancer progression. Conditioned medium from fibroblasts, which were extracted from the gastric wall of diffuse-type gastric carcinoma patients and transfected with LOXL2 siRNA, was co-cultured with gastric cancer cells. While untreated conditioned medium increased the migration and invasion, LOXL2 siRNA treatment of cancer-associated fibroblasts significantly decreased the migration and invasion of gastric cancer cells, underlining the tumor promoting role of LOXL2 in tumor-associated stroma cells [39]. Silencing of LOXL2 in cancer cells led also to a decrease of invasiveness in pancreatic [40] and gastric cancer [41] in vitro models.

The genes ITGB1 and ITGAV are members of the integrin gene family. Their gene products can form a heterodimeric integral membrane protein, which serves as
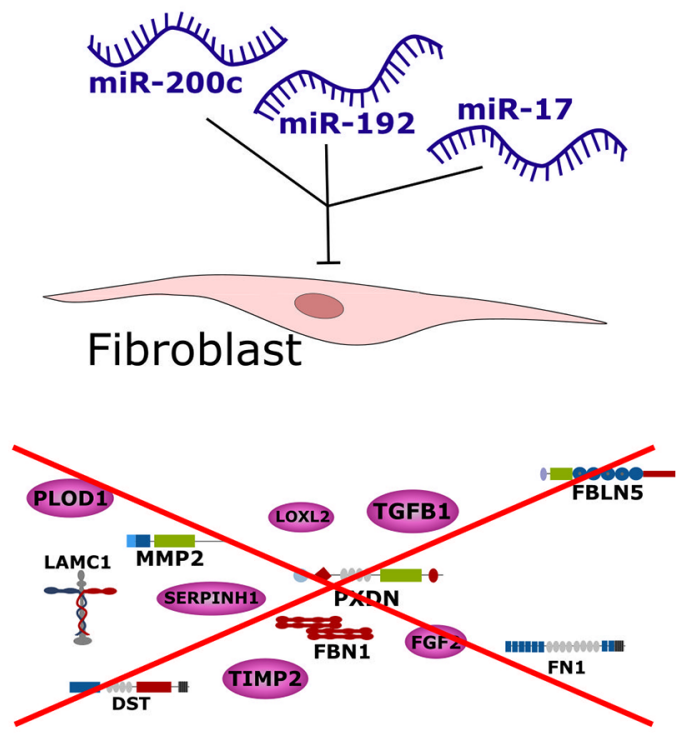

Less invasive phenotype

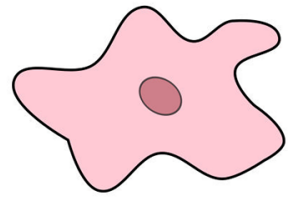

Colon cancer cell

Figure 6: Conceptional summary of the study. The stromal subgroup of colorectal cancer exhibits high metastatic potential of cancer cells and thus this subgroup has the worst survival prognosis compared to all other subgroups. Based on our study we conclude that by down-regulation of miR-200c, miR-192 and miR-17, tumor-associated fibroblasts can produce more ECM-related and invasion-promoting factors leading to an increased invasion of cancer cells and thus a highly invasive phenotype. Admission of these three miRNAs to tumorassociated fibroblasts in turn blocks transcription or translation of invasion-promoting proteins leading to a less invasive phenotype. 
a receptor for vitronectin, fibrinogen and other ligands. While overexpression of ITGAV was linked to progression and perineural invasion in colorectal cancer [42], ITGB1 expression in tumors was associated with shortened overall survival and shortened disease-free survival in a large cohort of patients with colorectal tumor [43]. RNAimediated knockdown of ITGB1 in human colorectal cancer cells significantly reduced the proliferation and invasion and resulted in slower tumor growth rates and smaller tumor volumes compared to control transfections in xenograft mouse models [44]. In MCF-7 breast cancer cells, knocking down ITGAV led to a significant inhibition of matrigel invasion [45].

Tissue Inhibitor of Metalloproteinases 2 (TIMP2) can bind various matrix metalloproteinases (MMPs), a large family of ECM-degrading endopeptidases. TIMP2 inactivates them irreversibly to prevent excessive destruction of the ECM network and to maintain tissue homeostasis. Roca et al. [46] performed an immunohistochemical analysis of TIMP2 in colorectal cancer samples and showed a specific staining not only in epithelial tumor cells but also in the ECM of the stromal compartment. High expression of TIMP2 was associated with bad outcome in colorectal cancer [46] and shortened disease-free and overall survival in human breast cancer [47]. SiRNA-mediated knockdown of TIMP2 in HCT-116 colon cancer resulted in a reduction of invasion of HCT116 cells in vitro [48].

The large family of matrix metallopeptidases (MMPs) plays a key role in tumor progression and metastasis as they actively drive proteolysis of physical barriers like the basement membrane which allows tumor cells to invade the surrounding tissue. They are also involved in epithelial-to-mesenchymal transition by shedding E-cadherin and cleavage of ECM-bound growth factors and cytokines (reviewed in [49]). MMP2 specifically degrades collagen IV, a major component of the basement membrane, but also elastin, fibronectin and laminin. Its enzymatic activity is mainly regulated by a major MMP antagonist, TIMP2 which prevents MMP2 from excessively ECM degrading. In the context of colorectal cancer, the mean activity of MMP2 was found to be around ten times higher in tumor tissue compared to normal mucosa [50]. Interestingly, Wiese et al. demonstrated that MMP2 expression was rather linked to stromal than epithelial tumor cells [51]. Dong and coworkers showed that shRNA-mediated knockdown of MMP2 in HT-29 and SW480 colon tumor cells clearly reduced their invasion capabilities in Boyden-chamber assays [52]. Further knockdown experiments using colorectal cancer cells revealed invasion or migration promoting roles for SPARC [53], FN1 [54] and FSCN1 [55]. The biological relevance of other miRNA target genes is discussed in Supplementary 2.3.

In summary, the literature evidenced the identified miRNA-regulated ECM genes to have an invasion promoting function in the tumor microenvironment of colorectal cancer and other tumor entities.

\section{MATERIALS AND METHODS}

\section{Acquisition of miRNA target genes}

As a resource for miRNA target genes, we downloaded experimentally validated, manually curated miRNA - target gene interactions from DIANA-TarBase v7.0 [11] and selected miRNA - target gene pairs from experiments performed in cells of human origin, irrespective of the applied detection method. After filtering, the dataset comprised of 322,145 unique miRNA - target gene pairs. Mature miRNA identifiers (typically with $-3 p$ or $-5 p$ specification) used in TarBase were mapped to pre-miRNA identifiers used in the experimental data according to the miRNA annotation data retrieved from miRBase [56]. Target genes of mature miRNAs belonging to the same pre-miRNA identifier were merged resulting in a unique set of target genes per pre-miRNA.

\section{The TCGA colon adenocarcinoma dataset and colorectal cancer subgroup definitions}

The TCGA colon adenocarcinoma dataset [2] used to establish our method comprises 271 tumor and eight control samples, for which both mRNA and miRNA expression data were available. Tumor samples originated from 146 male and 117 female patients with a median age at diagnosis of 67 years. Pathological TNM tumor staging based on the TNM-system [57] classified 42 tumors as stage I, 104 tumors as stage II, 72 tumors as stage III and 37 tumors as stage IV. Median overall survival was 409 days with a death rate of $21.2 \%$. Recurrence-free survival averaged 401 days with a recurrence rate of $18.5 \%$. The maximal follow-up period was 11.7 years. For our analysis, we used the molecular subgroup definitions identified by Guinney et al. [3], who combined different classifying methods and multiple colorectal cancer datasets (including the TCGA dataset) to define the subgroups, microsatellite instability immune (MSI immune), canonical, metabolic and mesenchymal, which have distinct clinical courses, expression profiles and pathway enrichments.

The MSI immune subgroup is characterized by microsatellite instability, immune cell infiltration and activation of immune response gene sets. Approximately $37 \%$ of the samples investigated by Guinney et al. [3] were assigned to the canonical subgroup, which was characterized by increased WNT and MYC signaling activity. Patients of this subgroup had the best overall survival. The miR-17-92 cluster (a direct MYC target, which includes miR-17, miR-18a, miR-19a, miR-20a, miR-19b-1, miR-92a-1), was overexpressed in canonical subgroup tumors. Biochemical pathways, such as glucose and amino acid metabolism, were dysregulated in the 
metabolic tumor subgroup, which also harbored a high proportion of KRAS and APC mutations and expressed low levels of miR-143 and six members of the let-7 family (let-7c, let-7e, miR-100, miR-125b-1, miR-125b-2 and miR-99a), which were associated with elevated KRAS expression. The metabolic subgroup was also epithelial in nature. Tumors from patients with the worst overall and relapse-free survival belonged to the mesenchymal subgroup, which also contained the highest proportion of stage III and IV tumors. MiRNAs previously shown to be tumor suppressive (miR-148a, miR-192 and members of the miR-200 family) were down-regulated in mesenchymal tumors. Guinney et al. [3] associated miR192 and miR-200 family down-regulation with epithelialto-mesenchymal transition and miR-148a down-regulation with TGF- $\beta$ signaling and matrix remodeling, all processes enriched in the mesenchymal tumor subgroup. TCGA samples with distinct molecular subgroup assignments defined by Guinney et al. [3] included 40 (MSI immune), 75 (canonical), 34 (metabolic), and 66 (mesenchymal) samples. Because our data show the mesenchymal tumor subgroup to be enriched with tumor-associated stromal cells, we use the term "stromal subgroup" in the text.

\section{The TCGA prostate adenocarcinoma dataset}

For performance testing and model comparison, we applied our method to another TCGA dataset comprising of 404 prostate adenocarcinoma samples for which miRNA and gene expression data were available [58]. The datasets were downloaded from the UCSC Cancer Browser (https://genome-cancer.ucsc.edu/proj/site/hgHeatmap).

We used RNA sequencing-based gene expression Level 3 data which were generated from sequences of the Illumina HiSeq 2000 RNA sequencing platform and processed using the RNASeq version 2 pipeline (https://wiki.nci.nih.gov/display/tcga). MiRNA expression was measured using the Illumina HiSeq 2000 and the Illumina Genome Analyzer platform. The data were provided as mapped reads per million miRNA (RPMM). Supplementary Table 1 provides an overview of the used datasets.

\section{Expression data of miRNA transfection experiments for validating the model predictions}

To validate potential miRNA target genes predicted by our model, published gene expression data of miRNA transfection experiments were downloaded from the Gene Expression Omnibus (https://www.ncbi.nlm.nih.gov/geo). MiRNA mimics or antagomiRs were transfected into various human cancer cell lines. Depending on the individual experimental design, different reagent concentrations and optional treatment of the cells prior to transfection were applied. Gene expression was measured at different time points using microarrays or RNA sequencing. We used data from 41 individual experiments of 12 different miRNAs: miR-17 (Ivanovska et al. [59], Doebele et al. [60], Martin et al. [61], Linsley et al. [62]), miR-20 (Ivanovska et al. [59], Linsley et al. [62]), miR106a (Ivanovska et al. [59]), miR-106b (Ivanovska et al. [59], Linsley et al. [62]), miR-92a (Borkowski et al. [63]), miR-192 (Linsley et al. [62], Georges et al. [64]), miR-215 (Linsley et al. [62], Georges et al. [64]), miR-16 (Linsley et al. [62]), miR-26b (Chen et al. [65]), miR-145 (Gregersen et al. [66]), miR-1 (Suzuki et al. [67]), and miR-7 (Hausser et al. [68]). Additionally, we collected data from 36 experiments of 19 different miRNAs to confirm the results of the analysis of the TCGA prostate adenocarcinoma dataset: miR-205 (Gandellini et al. [69], Boll et al. [70]), miR-29b (Takayama et al. [71]), miR135a (Kroiss et al. [72]), miR-145 (Ozen et al. [73], Kinoshita et al. [74], Nohata et al. [75]), miR-221 (Kneitz et al. [76]), miR-224 (Kristensen et al. [77]), miR-452 (Kristensen et al. [77]), miR-23b (Kinoshita et al. [74]), miR-24 (Kinoshita et al. [74]), miR-27b (Kinoshita et al. [74], Hudson et al. [78]), miR-143 (Kinoshita et al. [74]), miR-222 (Fuse et al. [79]), miR-31 (Fuse et al. [78], Lin et al. [80]), miR-106b (Hudson et al. [81]), miR-1 (Hudson et al. [78]), miR-206 (Hudson et al. [78]), miR-99a (Sun et al. [82]), miR-135b (Aakula et al. [83]), and miR-130a (Boll et al. [70]). Details about used cell lines, conditions, time points, miRNAs and experimental designs are listed in Supplementary Table 2.

\section{Cancer and stroma cell expression datasets}

To investigate gene and miRNA expression in tumor and tumor associated stroma cells, we investigated several publicly available datasets. Calon and colleagues [19] collected tissues containing both cancer and noncancer cells from six colorectal tumors. The tissue samples were minced and single cells were collected by sequential filtering. The filtered cells were stained with FAP- and hEPCAM antibody followed by fluorescence activated cell sorting (FACS) to obtain fibroblasts of the stroma and epithelial tumor cells. Cell type specific gene expression profiles were obtained using microarrays (Affymetrix HT HG-U133+). Furthermore, we analyzed expression data from the study of Nishida and co-workers [21]. Nishida et al. collected stromal and epithelial RNA samples from 13 colorectal cancers and four control tissues using laser capture microdissection for cell type separation. Both miRNA and gene expression were profiled using microarrays (gene expression: Agilent-014850, miRNA expression: Agilent-019118) for both cell types. Christensen et al. [20] also employed laser capture microdissection on colorectal tumor samples and compared the gene expression data from laser-dissected tumor cells and cultured tumor-associated fibroblasts. Finally, the dataset published by Scarpati and colleagues [22] provided miRNA expression profiles for tumor 
and stroma tissues which were microdissected from 57 surgical specimens taken from colorectal cancer patients. Supplementary Table 3 provides details about the datasets from these cell type specific experiments.

\section{Statistical analysis and model implementation}

Statistical analysis, data processing and setting up the optimization problem were all performed using $\mathrm{R}$ (https://www.r-project.org/, version 3.2.4). The Gurobi Optimizer (http://www.gurobi.com, version 6.5.2, academic license) was used to solve both the linear and the piecewise linear model.

\section{Data pre-processing}

We removed miRNAs and genes having no measurable expression intensities (RPKM $=0$ for all samples). Among the collection of miRNA target genes from TarBase, we selected only interactions measured in cells of human origin and mapped miRNA identifiers from TarBase to miRNA identifiers used in the TCGA dataset. For each miRNA - target gene pair, Pearson's correlation of miRNA- and target gene expression was computed, and only pairs with a negative correlation were considered for further analysis. Finally, both miRNA expression and gene expression datasets were z-normalized.

\section{Cell type-specific expression analysis of extracellular matrix-related target genes}

To support the hypothesis that extracellular matrix (ECM)-related genes identified in our analysis are particularly expressed by tumor-associated fibroblasts or stroma cells and not by tumor cells, we investigated expression data from four different studies [19-22], which we refer to by the paper first author for clarity. The Calon dataset provided gene expression profiles from fibroblasts and tumor cells separated by fluorescenceactivated cell sorting (FACS). Microdissection was used so separate tumor and stromal cells for gene (Christensen, Nishida) and miRNA (Nishida, Scarpati) expression profiles. Tumor-associated fibroblasts were separated from primary intestinal colon carcinoma samples using cell culture protocols in the study from Christensen. We tested genes and miRNAs for differential expression in tumor and non-tumor cells in each dataset individually. Pairwise Student's $t$-test followed by multiple-testing correction using the Benjamini-Hochberg method was performed to test for differential expression between the specific cell types. Gene-set enrichment analysis was performed using the "runGSA"-method from the piano package [84]. We chose the parameters "mean" as gene set statistics, "fdr" as multiple-testing correction method and repeated data randomization (parameter: "nPerm") 50,000 times. Only gene sets with adjusted p-values of at most 0.05 for distinct directionality ("pAdjDistinctDirDn" and
"pAdjDistinctDirUp") were considered to be significantly enriched. See Figure 1B for an illustrated workflow.

\section{Identification of additional miRNA target genes with binding site predictions}

For each candidate miRNA, we determined additional potential targets from the pool of 20 ECM target genes which resulted from the cell type specific expression analysis. We searched for miRNA binding-sites with the prediction tools MirWalk [85], PicTar [86], PITA [87], RNA22 [88] and TargetScan [89] (conserved and nonConserved). We considered a binding site predicted with at least one prediction tool as criterion for inclusion of the candidate gene as additional target gene of the respective miRNA. An overview over the additional target genes and identified binding sites with the corresponding prediction tool is presented in Supplementary Table 4.

\section{Cell lines and cell culture}

The human fibroblast cell lines CCD-18Co and MRC5 were purchased from ATCC (ATCC, VA, USA). CCD-18Co cells were cultured in DMEM medium with high glucose (1 $\mathrm{g} / \mathrm{L})$ and sodium pyruvate $(110 \mathrm{mg} / \mathrm{L})$ (Gibco, Carlsbad, CA, USA) supplemented with 10\% FCS superior (Biochrom, Berlin, Germany) without antibiotics at $37^{\circ} \mathrm{C}$ and $5 \%$ $\mathrm{CO} 2$. The cells were genotyped and tested for mycoplasma contamination. MRC5 cells were cultured in MEM medium (Gibco) supplemented with 10\% FCS superior without antibiotics at $37^{\circ} \mathrm{C}$ and $5 \% \mathrm{CO} 2$. HCT-116 cells were cultured in McCoy's 5a Medium Modified (Gibco) $+10 \%$ FCS superior without antibiotics at $37^{\circ} \mathrm{C}$ and $5 \% \mathrm{CO} 2$. Cells were tested for mycoplasma contamination.

\section{MiRNA transfection}

Fibroblasts were seeded in 6 well plates and cultured until they reached $80 \%$ confluence. Transfection was performed using Lipofectamine RNAiMAX reagent (Life technologies, CA, USA), which resulted in high transfection efficacy of $80 \%$ and low effect on cell viability for CCD-18Co cells (Supplementary Figure 6). The same protocol was used for MRC5 cells. Cells were transfected with $50 \mathrm{nM}$ mimic control-1 (ath-miR416), miR-192, miR-17 or miR-200c, respectively. Two days post transfection cells were harvested and cell pellets were shock-frozen and stored at $-80^{\circ} \mathrm{C}$ until further usage.

\section{Experimental validation of target gene repression by miRNAs}

RNA was isolated from frozen cell pellets using the miRNeasy Mini Kit (Qiagen, Hilden, Germany) according to the manufacturer's protocol. $500 \mathrm{ng}$ total RNA were reverse transcribed in a $20 \mu \mathrm{l}$ reaction utilizing oligo(dT)18 primer using the Transcriptor First Strand 
cDNA Synthesis Kit (Roche Applied Science, Mannheim, Germany). For qPCR analysis $2 \mu 1$ 1:5 diluted cDNA were used in a $20 \mu \mathrm{l}$ reaction using Power SYBR green PCR Mastermix (Applied Biosystems, Foster City, CA, USA). The used qPCR primers are listed in Supplementary Table 5. All primers were tested for specificity and efficacy. For all samples, three technical replicates were performed and relative expression was calculated with the $\Delta \Delta \mathrm{Ct}$ method according to the manufacturer's protocol. To identify suitable endogenous normalization control genes which were not altered by the tested miRNA, we revised the well-established house-keeping genes GAPDH, RPL19, TBP, HMBS, HPRT1, UBC and ACTB for potential miRNA binding-sites by utilizing the target gene prediction tools miRmap [90], TarBase [11], RNA22 [88], PicTar [86], TargetScan [89], miRanda [91], miRWalk [85] and PITA [87]. An overview over the tested house-keeping genes and identified binding sites with the corresponding prediction tool is presented in Supplementary Table 6. We considered a binding site predicted with at least one prediction tool as criterion for exclusion of the target gene to be used as a control. Due to the mutual exclusive binding site predictions of the tested control genes, choosing a unique control gene for all three miRNAs was not possible. Instead, we selected TBP as a control gene for miR-192 and miR-17 and UBC as a control gene for miR-200c. We considered a target gene with $\log 2\left(2^{\wedge}\right.$ $\Delta \Delta \mathrm{Ct})<=-0.5$ to be effectively down-modulated by the miRNA. Upper and lower error bars were calculated as $\log 2\left(2^{\wedge}-\Delta \Delta C \mathrm{t}\right)+/-\Delta \Delta \mathrm{Ct}$ error propagation value.

\section{Western blot assay}

Three days post transfection of fibroblast cells the supernatant was collected and used for detection of MMP2 protein levels by Western blot. Samples were heat denatured for $5 \mathrm{~min}$ at $96^{\circ} \mathrm{C}$ and loaded onto polyacrylamide gels (12\%). After electro-transfer of separated protein extracts, nitrocellulose membranes were blocked with 5\% BSA for $1 \mathrm{~h}$ at RT. The primary antibody (MMP2 pAB ALX-210-753-R500, Enzo) was incubated at $4{ }^{\circ} \mathrm{C} \mathrm{o} / \mathrm{n}$ in blocking solution. After extensive washing, membranes were incubated for $1 \mathrm{~h}$ at RT with the corresponding secondary antibodies (anti-rabbit) coupled to horse reddish peroxidase. Protein signals were then detected with ECL-Prime reagent (GE Healthcare) and measurements were performed on a ChemiDoc XRS system (BioRad). Densitometric quantification of protein bands was performed using ImageLab software.

\section{Invasion assay}

CCD-18Co cells were seeded in 6 well plates and grown to $80 \%$ confluency until they were transfected with 50 nM miRNA (mock, miR-192, miR-17 or miR200c) and cultured for 3 days. The invasion assay was performed using 96 well Boyden-chamber plates $(8 \mu \mathrm{m}$ pore size, Corning, Big Flats, NY, USA), which were coated with $10 \mu \mathrm{g}$ matrigel per well. Fibroblasts were harvested and 3 individually transfected wells were pooled for each condition. 1.5x105 CCD-18Co cells were seeded in outer wells of the Boyden-chamber in $150 \mu \mathrm{l}$ DMEM medium supplemented with $10 \%$ FCS. HCT-116 colon cancer cells were seeded in the inner wells with a cell number of $5 \times 104$ in $50 \mu \mathrm{l}$ per well. HCT-116 cells were kept in medium without serum. After $24 \mathrm{~h}$ incubation at $37^{\circ} \mathrm{C}$ invasion was measured. Cells were lysed with $1 \mathrm{x}$ cell dissociation solution (CDS) (Trevigen, Gaithersburg, MD, USA) supplemented with calcein-AM. HTS Transwell 96 well black receiver plates (Corning, Big Flats, NY, USA) were pre-incubated with $\mathrm{PBS}$ at $37^{\circ} \mathrm{C}$. Meanwhile, the medium was removed from the outer wells of the Boyden-chamber plates. Washing of outer wells was performed very carefully by pipetting $150 \mu \mathrm{l}$ PBS in and out. The PBS from the black receiver plate was discarded and $100 \mu$ of $1 x$ CDS-calcein was pipetted in each well. The inlay from the transwell plate was transferred carefully to the receiver plate avoiding any contacts. The plates were incubated for $1 \mathrm{~h}$ at $37^{\circ} \mathrm{C}$ and knocking at each side of the plate was performed every 15 min to ensure complete dissociation of cells attached to the lower side of the gel membrane. Finally, fluorescence was measured using $485 \mathrm{~nm}$ as excitation wavelength, $538 \mathrm{~nm}$ as the emission wavelength and integration of $60 \mathrm{~ms}$.

\section{Proliferation assay}

Fibroblast cells were transfected exactly as for the invasion assay. Three days post transfection the supernatant of transfected fibroblasts was collected. HCT-116 cells were seeded in 96 well plates with $5 \times 10^{4}$ cells per well as for the invasion assay. After attachment of the colon cancer cells their medium was removed and replaced with the supernatant of the transfected fibroblasts. Proliferation of HCT-116 cells was measured with the XTT cell proliferation assay kit from PromoKine (PromoCell, Heidelberg, Germany) according to the manufacturer's protocol. To test for significance reduction of proliferation, we applied one-way ANOVA Dunnett's multiple comparison test using the multcomp [92] R-package with scrambled miRNA transfection as control (mimic control-1). Proliferation is presented as mean optical density (OD) at $450 \mathrm{~nm}$ absorbance +/- standard deviation.

\section{CONCLUSIONS}

We identified miR-192, miR-17, miR-200c as miRNAs that down-regulate stromal target genes for ECM remodeling. Restoring miR-192, miR-17 and/or miR-200c 
expression in tumor stroma could reduce the invasive capacity of colon cancer cells. Our findings provide intriguing potential for therapeutic options, however, a final proof of the involvement of the proposed miRNAs and target genes in the pathogenesis of colorectal cancer requires further, in-depth investigations employing coculture systems and animal models to pave the way for clinical applications.

\section{Author contributions}

VA and RK designed the study. VA performed the computational analysis. TK, WO, DE, AB and SE designed and performed the experiments. MO conceptualized the Mixed Integer Linear Programming implementation to set up the piecewise linear model. AK provided software to reduce GO enrichment terms. VA, RK and TK wrote the manuscript. All authors approved the manuscript.

\section{ACKNOWLEDGMENTS}

We thank Joao Saraiva and Kathy Astrahantseff for proof-reading the manuscript. The human colon carcinoma cell line HCT-116 was kindly provided by Evi Frei.

\section{CONFLICTS OF INTEREST}

The authors declare no potential conflicts of interest.

\section{FUNDING}

This work was supported by the Federal Ministry of Education and Research (BMBF), Germany, FKZ 01ZX1302B, 01ZX1602B (CancerTel-Sys) and 01EO1002, 01EO1502 (IFB/CSCC), and the Deutsche Forschungsgemeinschaft within the graduate program Jena School for Microbial Communication.

\section{REFERENCES}

1. Stewart BW, Wild CPW. World Cancer Report 2014. Lyon; 2014.

2. Cancer Genome Atlas Network TCGA. Comprehensive molecular characterization of human colon and rectal cancer. Nature. 2012; 487:330-7. https://doi.org/10.1038/nature11252.

3. Guinney J, Dienstmann R, Wang X, de Reyniès A, Schlicker A, Soneson C, Marisa L, Roepman P, Nyamundanda G, Angelino P, Bot BM, Morris JS, Simon IM, et al. The consensus molecular subtypes of colorectal cancer. Nat Med. 2015; 21:1350-6. https://doi.org/10.1038/nm.3967.

4. Esquela-Kerscher A, Slack FJ. Oncomirs - microRNAs with a role in cancer. Nat Rev Cancer. 2006; 6:259-69. https://doi.org/10.1038/nrc1840.
5. Peng Y, Croce CM. The role of MicroRNAs in human cancer. Signal Transduct Target Ther. 2016; 1. https://doi.org/10.1038/sigtrans.2015.4.

6. Strubberg AM, Madison BB. MicroRNAs in the etiology of colorectal cancer: pathways and clinical implications. Dis Model Mech. 2017; 10:197-214. https://doi.org/10.1242/dmm.027441.

7. Rupaimoole R, Slack FJ. MicroRNA therapeutics: towards a new era for the management of cancer and other diseases. Nat Rev Drug Discov. 2017; 16:203-22. https://doi. org/10.1038/nrd.2016.246.

8. Beg MS, Brenner AJ, Sachdev J, Borad M, Kang YK, Stoudemire J, Smith S, Bader AG, Kim S, Hong DS. Phase I study of MRX34, a liposomal miR-34a mimic, administered twice weekly in patients with advanced solid tumors. Invest New Drugs. 2017; 35:180-8. https://doi.org/10.1007/s10637-016-0407-y.

9. Kozomara A, Hunt S, Ninova M, Griffiths-Jones S, Ronshaugen M. Target repression induced by endogenous microRNAs: large differences, small effects. PLoS One. 2014; 9:e104286.

10. Mullokandov G, Baccarini A, Ruzo A, Jayaprakash $\mathrm{AD}$, Tung N, Israelow B, Evans MJ, Sachidanandam R, Brown BD. High-throughput assessment of microRNA activity and function using microRNA sensor and decoy libraries. Nat Methods. 2012; 9:840-6. https://doi.org/10.1038/nmeth.2078.

11. Vlachos IS, Paraskevopoulou MD, Karagkouni D, Georgakilas G, Vergoulis T, Kanellos I, Anastasopoulos IL, Maniou S, Karathanou K, Kalfakakou D, Fevgas A, Dalamagas T, Hatzigeorgiou AG. DIANA-TarBase v7.0: indexing more than half a million experimentally supported miRNA:mRNA interactions. Nucleic Acids Res. 2015; 43:D153-9. https://doi.org/10.1093/nar/gku1215.

12. Poos AM, Maicher A, Dieckmann AK, Oswald M, Eils R, Kupiec M, Luke B, König R. Mixed Integer Linear Programming based machine learning approach identifies regulators of telomerase in yeast. Nucleic Acids Res. 2016; 44: e93-e93. https://doi.org/10.1093/nar/gkw111.

13. Bonnans C, Chou J, Werb Z. Remodelling the extracellular matrix in development and disease. Nat Rev Mol Cell Biol. 2014; 15:786-801. https://doi.org/10.1038/nrm3904.

14. Pickup MW, Mouw JK, Weaver VM. The extracellular matrix modulates the hallmarks of cancer. EMBO Rep. 2014; 15:1243-53. https://doi.org/10.15252/embr.201439246.

15. Isella C, Terrasi A, Bellomo SE, Petti C, Galatola G, Muratore A, Mellano A, Senetta R, Cassenti A, Sonetto C, Inghirami G, Trusolino L, Fekete Z, et al. Stromal contribution to the colorectal cancer transcriptome. Nat Genet. 2015; 47:312-9. https://doi.org/10.1038/ng.3224.

16. Calon A, Lonardo E, Berenguer-Llergo A, Espinet E, Hernando-Momblona X, Iglesias M, Sevillano M, PalomoPonce S, Tauriello DVF, Byrom D, Cortina C, Morral C, Barceló C, et al. Stromal gene expression defines 
poor-prognosis subtypes in colorectal cancer. Nat Genet. 2015; 47:320-9. https://doi.org/10.1038/ng.3225.

17. Bremnes RM, Dønnem T, Al-Saad S, Al-Shibli K, Andersen S, Sirera R, Camps C, Marinez I, Busund LT. The role of tumor stroma in cancer progression and prognosis: emphasis on carcinoma-associated fibroblasts and nonsmall cell lung cancer. J Thorac Oncol. 2011; 6:209-17. https://doi.org/10.1097/JTO.0b013e3181f8albd.

18. Shiga K, Hara M, Nagasaki T, Sato T, Takahashi H, Takeyama H. Cancer-associated fibroblasts: their characteristics and their roles in tumor growth. Cancers (Basel). 2015; 7:244358. https://doi.org/10.3390/cancers7040902.

19. Calon A, Espinet E, Palomo-Ponce S, Tauriello DVF, Iglesias M, Céspedes MV, Sevillano M, Nadal C, Jung P, Zhang XH, Byrom D, Riera A, Rossell D, et al. Dependency of colorectal cancer on a TGF- $\beta$-driven program in stromal cells for metastasis initiation. Cancer Cell. 2012; 22:571-84. https://doi.org/10.1016/j.ccr.2012.08.013.

20. Christensen J, El-Gebali S, Natoli M, Sengstag T, Delorenzi M, Bentz S, Bouzourene H, Rumbo M, Felsani A, Siissalo $\mathrm{S}$, Hirvonen J, Vila MR, Saletti P, et al. Defining new criteria for selection of cell-based intestinal models using publicly available databases. BMC Genomics. 2012; 13:274. https://doi.org/10.1186/1471-2164-13-274.

21. Nishida N, Nagahara M, Sato T, Mimori K, Sudo T, Tanaka F, Shibata K, Ishii H, Sugihara K, Doki Y, Mori M. Microarray analysis of colorectal cancer stromal tissue reveals upregulation of two oncogenic miRNA clusters. Clin Cancer Res. 2012; 18:3054-70. https://doi.org/10.1158/1078-0432.CCR-11-1078.

22. Della Vittoria Scarpati G, Calura E, Di Marino M, Romualdi C, Beltrame L, Malapelle U, Troncone G, De Stefano A, Pepe S, De Placido S, D'Incalci M, Marchini $\mathrm{S}$, Carlomagno C. Analysis of differential miRNA expression in primary tumor and stroma of colorectal cancer patients. Biomed Res Int. 2014; 2014:840921. https://doi.org/10.1155/2014/840921.

23. Kessenbrock K, Plaks V, Werb Z. Matrix metalloproteinases: regulators of the tumor microenvironment. Cell. 2010; 141:52-67. https://doi.org/10.1016/j.cell.2010.03.015.

24. Gaggioli C, Hooper S, Hidalgo-Carcedo C, Grosse R, Marshall JF, Harrington K, Sahai E. Fibroblastled collective invasion of carcinoma cells with differing roles for RhoGTPases in leading and following cells. Nat Cell Biol. 2007; 9:1392-400. https://doi.org/10.1038/ncb1658.

25. Li J, Jia Z, Kong J, Zhang F, Fang S, Li X, Li W, Yang X, Luo Y, Lin B, Liu T. Carcinoma-associated fibroblasts lead the invasion of salivary gland adenoid cystic carcinoma cells by creating an invasive track. PLoS One. 2016; 11:e0150247. https://doi.org/10.1371/journal.pone.0150247.

26. Geng L, Chaudhuri A, Talmon G, Wisecarver JL, Are C, Brattain M, Wang J. MicroRNA-192 suppresses liver metastasis of colon cancer. Oncogene. 2014; 33:5332-40. https://doi.org/10.1038/onc.2013.478.

27. Yang SY, Choi SA, Lee JY, Park AK, Wang KC, Phi JH, Koh EJ, Park WY, Park SH, Hwang DW, Jung HW, Kim SK. miR-192 suppresses leptomeningeal dissemination of medulloblastoma by modulating cell proliferation and anchoring through the regulation of DHFR, integrins, and CD47. Oncotarget. 2015; 6:43712-30. https://doi.org/10.18632/oncotarget.6227.

28. Korpal M, Lee ES, Hu G, Kang Y. The miR-200 family inhibits epithelial-mesenchymal transition and cancer cell migration by direct targeting of E-cadherin transcriptional repressors ZEB1 and ZEB2. J Biol Chem. 2008; 283:149104. https://doi.org/10.1074/jbc.C800074200.

29. Bai WD, Ye XM, Zhang MY, Zhu HY, Xi WJ, Huang X, Zhao J, Gu B, Zheng GX, Yang AG, Jia LT. MiR-200c suppresses TGF- $\beta$ signaling and counteracts trastuzumab resistance and metastasis by targeting ZNF217 and ZEB1 in breast cancer. Int J Cancer. 2014; 135:1356-68. https://doi.org/10.1002/ijc.28782.

30. Hur K, Toiyama Y, Takahashi M, Balaguer F, Nagasaka T, Koike J, Hemmi H, Koi M, Boland CR, Goel A. MicroRNA-200c modulates epithelialto-mesenchymal transition (EMT) in human colorectal cancer metastasis. Gut. 2013; 62:1315-26. https://doi.org/10.1136/gutjnl-2011-301846.

31. Chen J, Wang W, Zhang Y, Hu T, Chen Y. The roles of miR-200c in colon cancer and associated molecular mechanisms. Tumour Biol. 2014; 35:6475-83. https://doi.org/10.1007/s13277-014-1860-x.

32. Olive V, Jiang I, He L. mir-17-92, a cluster of miRNAs in the midst of the cancer network. Int J Biochem Cell Biol. 2010; 42:1348-54. https://doi.org/10.1016/j.biocel.2010.03.004.

33. Ottman R, Levy J, Grizzle WE, Chakrabarti R. The other face of miR-17-92a cluster, exhibiting tumor suppressor effects in prostate cancer. Oncotarget. 2016; 7:73739-53. https://doi.org/10.18632/oncotarget.12061.

34. Knudsen KN, Nielsen BS, Lindebjerg J, Hansen TF, Holst $\mathrm{R}$, Sørensen FB. microRNA-17 is the most up-regulated member of the miR-17-92 cluster during early colon cancer evolution. PLoS One. 2015; 10:e0140503.

35. Xiao Q, Ge G. Lysyl oxidase, extracellular matrix remodeling and cancer metastasis. Cancer Microenviron. 2012; 5:26173. https://doi.org/10.1007/s12307-012-0105-z.

36. Wu L, Zhu Y. The function and mechanisms of action of LOXL2 in cancer (Review). Int J Mol Med. 2015; 36:1200 4. https://doi.org/10.3892/ijmm.2015.2337.

37. Torres S, Garcia-Palmero I, Herrera M, Bartolome RA, Pena C, Fernandez-Acenero MJ, Padilla G, Pelaez-Garcia A, Lopez-Lucendo M, Rodriguez-Merlo R, de Herreros AG, Bonilla F, Casal JI. LOXL2 Is highly expressed in cancer-associated fibroblasts and associates to poor colon 
cancer survival. Clin Cancer Res. 2015; 21:4892-902. https://doi.org/10.1158/1078-0432.CCR-14-3096.

38. Fong SFT, Dietzsch E, Fong KSK, Hollosi P, Asuncion L, He Q, Parker MI, Csiszar K. Lysyl oxidase-like 2 expression is increased in colon and esophageal tumors and associated with less differentiated colon tumors. Genes Chromosomes Cancer. 2007; 46:644-55. https://doi.org/10.1002/gcc.20444.

39. Kasashima H, Yashiro M, Kinoshita H, Fukuoka T, Morisaki T, Masuda G, Sakurai K, Kubo N, Ohira M, Hirakawa K. Lysyl oxidase-like 2 (LOXL2) from stromal fibroblasts stimulates the progression of gastric cancer. Cancer Lett. 2014; 354:438 46. https://doi.org/10.1016/j.canlet.2014.08.014.

40. Park JS, Lee JH, Lee YS, Kim JK, Dong SM, Yoon DS. Emerging role of LOXL2 in the promotion of pancreas cancer metastasis. Oncotarget. 2016; 7:42539-52. https://doi.org/10.18632/oncotarget.9918.

41. Peng L, Ran YL, Hu H, Yu L, Liu Q, Zhou Z, Sun YM, Sun LC, Pan J, Sun LX, Zhao P, Yang ZH. Secreted LOXL2 is a novel therapeutic target that promotes gastric cancer metastasis via the $\mathrm{Src} /$ FAK pathway. Carcinogenesis. 2009; 30:1660-9. https://doi.org/10.1093/carcin/bgp178.

42. Waisberg J, De Souza Viana L, Affonso Junior RJ, Silva SR, Denadai MV, Margeotto FB, De Souza CS, Matos D. Overexpression of the ITGAV gene is associated with progression and spread of colorectal cancer. Anticancer Res. 2014; 34:5599-607.

43. Liu QZ, Gao XH, Chang WJ, Gong HF, Fu CG, Zhang W, Cao GW. Expression of ITGB1 predicts prognosis in colorectal cancer: a large prospective study based on tissue microarray. Int J Clin Exp Pathol. 2015; 8:12802-10.

44. Song J, Zhang J, Wang J, Wang J, Guo X, Dong W. $\beta 1$ integrin mediates colorectal cancer cell proliferation and migration through regulation of the Hedgehog pathway. Tumour Biol. 2015; 36:2013-21. https://doi.org/10.1007/s13277-014-2808-x.

45. Schwickert A, Weghake E, Brüggemann K, Engbers A, Brinkmann BF, Kemper B, Seggewiß J, Stock C, Ebnet K, Kiesel L, Riethmüller C, Götte M. microRNA miR-142-3p inhibits breast cancer cell invasiveness by synchronous targeting of WASL, integrin alpha V, and additional cytoskeletal elements. PLoS One. 2015; 10:e0143993. https://doi.org/10.1371/journal.pone.0143993.

46. Roca F, Mauro LV, Morandi A, Bonadeo F, Vaccaro C, Quintana GO, Specterman S, de Kier Joffé EB, Pallotta MG, Puricelli LI, Lastiri J. Prognostic value of E-cadherin, beta-catenin, MMPs (7 and 9), and TIMPs (1 and 2) in patients with colorectal carcinoma. J Surg Oncol. 2006; 93:151-60. https://doi.org/10.1002/jso.20413.

47. Remacle A, McCarthy K, Noël A, Maguire T, McDermott E, O'Higgins N, Foidart JM, Duffy MJ. High levels of TIMP-2 correlate with adverse prognosis in breast cancer. Int J Cancer. 2000; 89:118-21.
48. Zhang M, Liu Y, Feng H, Bian X, Zhao W, Yang Z, Gu B, Li Z, Liu Y. CD133 affects the invasive ability of HCT116 cells by regulating TIMP-2. Am J Pathol. 2013; 182:565-76. https://doi.org/10.1016/J.AJPATH.2012.10.015.

49. Gialeli C, Theocharis AD, Karamanos NK. Roles of matrix metalloproteinases in cancer progression and their pharmacological targeting. FEBS J. 2011; 278:16-27. https://doi.org/10.1111/j.1742-4658.2010.07919.x.

50. Murnane MJ, Cai J, Shuja S, McAneny D, Klepeis V, Willett JB. Active MMP-2 effectively identifies the presence of colorectal cancer. Int J Cancer. 2009; 125:2893-902. https://doi.org/10.1002/ijc.24682.

51. Wiese AH, Auer J, Lassmann S, Nährig J, Rosenberg R, Höfler $\mathrm{H}$, Rüger R, Werner M. Identification of gene signatures for invasive colorectal tumor cells. Cancer Detect Prev. 2007; 31:282-95.

52. Dong $\mathrm{W}$, Li $\mathrm{H}$, Zhang $\mathrm{Y}$, Yang $\mathrm{H}$, Guo $\mathrm{M}$, Li L, Liu T. Matrix metalloproteinase 2 promotes cell growth and invasion in colorectal cancer. Acta Biochim Biophys Sin (Shanghai). 2011; 43:840-8. https://doi.org/10.1093/abbs/gmr085.

53. Zhang S, Jin J, Tian $\mathrm{X}$, Wu L. hsa-miR-29c-3p regulates biological function of colorectal cancer by targeting SPARC. Oncotarget. 2017; 8:104508-24. https://doi.org/10.18632/oncotarget.22356.

54. Cai X, Liu C, Zhang TN, Zhu YW, Dong X, Xue P. Down-regulation of FN1 inhibits colorectal carcinogenesis by suppressing proliferation, migration, and invasion. J Cell Biochem. 2018; 119:4717-28. https://doi.org/10.1002/jcb.26651.

55. Zheng K, Liu W, Liu Y, Jiang C, Qian Q. MicroRNA133a suppresses colorectal cancer cell invasion by targeting Fascin1. Oncol Lett. 2015; 9:869-74. https://doi.org/10.3892/ol.2014.2753.

56. Kozomara A, Griffiths-Jones S. miRBase: annotating high confidence microRNAs using deep sequencing data. Nucleic Acids Res. 2014; 42:D68-73. https://doi.org/10.1093/nar/gkt1181.

57. Edge SB, American Joint Committee on Cancer. AJCC cancer staging manual. Springer; 2010. 648 p.

58. Abeshouse A, Ahn J, Akbani R, Ally A, Amin S, Andry CD, Annala M, Aprikian A, Armenia J, Arora A, Auman JT, Balasundaram M, Balu S, et al. The molecular taxonomy of primary prostate cancer. Cell. 2015; 163:1011-25. https://doi.org/10.1016/j.cell.2015.10.025.

59. Ivanovska I, Ball AS, Diaz RL, Magnus JF, Kibukawa M, Schelter JM, Kobayashi SV, Lim L, Burchard J, Jackson AL, Linsley PS, Cleary MA. MicroRNAs in the miR$106 \mathrm{~b}$ family regulate $\mathrm{p} 21 / \mathrm{CDKN} 1 \mathrm{~A}$ and promote cell cycle progression. Mol Cell Biol. 2008; 28:2167-74. https://doi.org/10.1128/MCB.01977-07.

60. Doebele C, Bonauer A, Fischer A, Scholz A, Reiss Y, Urbich C, Hofmann WK, Zeiher AM, Dimmeler S. Members of the microRNA-17-92 cluster exhibit a cell-intrinsic 
antiangiogenic function in endothelial cells. Blood. 2010; 115:4944-50. https://doi.org/10.1182/blood-2010-01-264812.

61. Martin HC, Wani S, Steptoe AL, Krishnan K, Nones K, Nourbakhsh E, Vlassov A, Grimmond SM, Cloonan N. Imperfect centered miRNA binding sites are common and can mediate repression of target mRNAs. Genome Biol. 2014; 15:R51. https://doi.org/10.1186/gb-2014-15-3-r51.

62. Linsley PS, Schelter J, Burchard J, Kibukawa M, Martin MM, Bartz SR, Johnson JM, Cummins JM, Raymond CK, Dai H, Chau N, Cleary M, Jackson AL, et al. Transcripts targeted by the MicroRNA-16 family cooperatively regulate cell cycle progression. Mol Cell Biol. 2007; 27:2240-52. https://doi.org/10.1128/MCB.02005-06.

63. Borkowski R, Du L, Zhao Z, McMillan E, Kosti A, Yang CR, Suraokar M, Wistuba II, Gazdar AF, Minna JD, White MA, Pertsemlidis A. Genetic mutation of p53 and suppression of the mir-17-92 cluster are synthetic lethal in non-small cell lung cancer due to upregulation of vitamin d signaling. Cancer Res. 2015; 75:666-75. https://doi.org/10.1158/0008-5472.CAN-14-1329.

64. Georges SA, Biery MC, Kim SY, Schelter JM, Guo J, Chang AN, Jackson AL, Carleton MO, Linsley PS, Cleary MA, Chau BN. Coordinated regulation of cell cycle transcripts by $\mathrm{p} 53$-inducible microRNAs, miR192 and miR-215. Cancer Res. 2008; 68:10105-12. https://doi.org/10.1158/0008-5472.CAN-08-1846.

65. Chen CYA, Chang JT, Ho YF, Shyu AB. MiR-26 downregulates $\mathrm{TNF}-\alpha / \mathrm{NF}-\kappa \mathrm{B}$ signalling and IL- 6 expression by silencing HMGA1 and MALT1. Nucleic Acids Res. 2016; 44:3772-87. https://doi.org/10.1093/nar/gkw205.

66. Gregersen LH, Jacobsen AB, Frankel LB, Wen J, Krogh A, Lund AH. MicroRNA-145 targets YES and STAT1 in colon cancer cells. PLoS One. 2010; 5:e8836.

67. Suzuki H, Takatsuka S, Akashi H, Yamamoto E, Nojima M, Maruyama R, Kai M, Yamano HO, Sasaki Y, Tokino T, Shinomura Y, Imai K, Toyota M. Genome-wide profiling of chromatin signatures reveals epigenetic regulation of MicroRNA genes in colorectal cancer. Cancer Res. 2011; 71:5646-58. https://doi.org/10.1158/0008-5472.CAN-11-1076.

68. Hausser J, Landthaler M, Jaskiewicz L, Gaidatzis D, Zavolan $\mathrm{M}$. Relative contribution of sequence and structure features to the mRNA binding of Argonaute/EIF2C-miRNA complexes and the degradation of miRNA targets. Genome Res. 2009; 19:2009-20. https://doi.org/10.1101/gr.091181.109.

69. Gandellini P, Folini M, Longoni N, Pennati M, Binda M, Colecchia M, Salvioni R, Supino R, Moretti R, Limonta P, Valdagni R, Daidone MG, Zaffaroni N. miR-205 Exerts Tumor-suppressive functions in human prostate through downregulation of protein kinase C. Cancer Res. 2009; 69:2287-95. https://doi.org/10.1158/0008-5472.CAN-08-2894.

70. Boll K, Reiche K, Kasack K, Mörbt N, Kretzschmar AK, Tomm JM, Verhaegh G, Schalken J, von Bergen M, Horn F, Hackermüller J. MiR-130a, miR-203 and miR205 jointly repress key oncogenic pathways and are downregulated in prostate carcinoma. Oncogene. 2013; 32:277-85. https://doi.org/10.1038/onc.2012.55.

71. Takayama K, Misawa A, Suzuki T, Takagi K, Hayashizaki Y, Fujimura T, Homma Y, Takahashi S, Urano T, Inoue $\mathrm{S}$. TET2 repression by androgen hormone regulates global hydroxymethylation status and prostate cancer progression. Nat Commun. 2015; 6:8219. https://doi.org/10.1038/ncomms9219.

72. Kroiss A, Vincent S, Decaussin-Petrucci M, Meugnier E, Viallet J, Ruffion A, Chalmel F, Samarut J, Allioli N. Androgen-regulated microRNA-135a decreases prostate cancer cell migration and invasion through downregulating ROCK1 and ROCK2. Oncogene. 2015; 34:2846-55. https://doi.org/10.1038/onc.2014.222.

73. Ozen M, Karatas OF, Gulluoglu S, Bayrak OF, Sevli S, Guzel E, Ekici ID, Caskurlu T, Solak M, Creighton CJ, Ittmann M. Overexpression of miR-145-5p inhibits proliferation of prostate cancer cells and reduces SOX2 expression. Cancer Invest. 2015; 33:251-8. https://doi.org/10.3109/07357907.2015.1025407.

74. Kinoshita $T$, Nohata N, Hanazawa $T$, Kikkawa N, Yamamoto N, Yoshino H, Itesako T, Enokida H, Nakagawa M, Okamoto Y, Seki N. Tumour-suppressive microRNA29s inhibit cancer cell migration and invasion by targeting laminin-integrin signalling in head and neck squamous cell carcinoma. Br J Cancer. 2013; 109:2636-45. https://doi.org/10.1038/bjc.2013.607.

75. Nohata N, Hanazawa T, Kikkawa N, Sakurai D, Fujimura L, Chiyomaru T, Kawakami K, Yoshino H, Enokida H, Nakagawa M, Katayama A, Harabuchi Y, Okamoto $\mathrm{Y}$, et al. Tumour suppressive microRNA-874 regulates novel cancer networks in maxillary sinus squamous cell carcinoma. $\mathrm{Br}$ J Cancer. 2011; 105:833-41. https://doi.org/10.1038/bjc.2011.311.

76. Kneitz B, Krebs M, Kalogirou C, Schubert M, Joniau S, van Poppel H, Lerut E, Kneitz S, Scholz CJ, Strobel P, Gessler M, Riedmiller H, Spahn M. Survival in patients with highrisk prostate cancer is predicted by miR-221, which regulates proliferation, apoptosis, and invasion of prostate cancer cells by inhibiting IRF2 and SOCS3. Cancer Res. 2014; 74:2591603. https://doi.org/10.1158/0008-5472.CAN-13-1606.

77. Kristensen H, Haldrup C, Strand S, Mundbjerg K, Mortensen MM, Thorsen K, Ostenfeld MS, Wild PJ, Arsov C, Goering W, Visakorpi T, Egevad L, Lindberg $\mathrm{J}$, et al. Hypermethylation of the GABRE-miR-452miR-224 promoter in prostate cancer predicts biochemical recurrence after radical prostatectomy. Clin Cancer Res. $2014 ; 20$.

78. Hudson RS, Yi M, Esposito D, Watkins SK, Hurwitz AA, Yfantis HG, Lee DH, Borin JF, Naslund MJ, Alexander RB, Dorsey TH, Stephens RM, Croce CM, et al. MicroRNA-1 is a candidate tumor suppressor and prognostic marker in human prostate cancer. Nucleic Acids Res. 2012; 40:3689703. https://doi.org/10.1093/nar/gkr1222. 
79. Fuse M, Kojima S, Enokida H, Chiyomaru T, Yoshino H, Nohata N, Kinoshita T, Sakamoto S, Naya Y, Nakagawa M, Ichikawa T, Seki N. Tumor suppressive microRNAs (miR222 and miR-31) regulate molecular pathways based on microRNA expression signature in prostate cancer. J Hum Genet. 2012; 57:691-9. https://doi.org/10.1038/jhg.2012.95.

80. Lin PC, Chiu YL, Banerjee S, Park K, Mosquera JM, Giannopoulou E, Alves P, Tewari AK, Gerstein MB, Beltran H, Melnick AM, Elemento O, Demichelis F, et al. Epigenetic repression of miR-31 disrupts androgen receptor homeostasis and contributes to prostate cancer progression. Cancer Res. 2013; 73:1232-44. https://doi.org/10.1158/0008-5472.CAN-12-2968.

81. Hudson RS, Yi M, Esposito D, Glynn SA, Starks AM, Yang Y, Schetter AJ, Watkins SK, Hurwitz AA, Dorsey TH, Stephens RM, Croce CM, Ambs S. MicroRNA106b-25 cluster expression is associated with early disease recurrence and targets caspase-7 and focal adhesion in human prostate cancer. Oncogene. 2013; 32:4139-47. https://doi.org/10.1038/onc.2012.424.

82. Sun D, Lee YS, Malhotra A, Kim HK, Matecic M, Evans C, Jensen RV, Moskaluk CA, Dutta A. miR99 family of MicroRNAs suppresses the expression of prostate-specific antigen and prostate cancer cell proliferation. Cancer Res. 2011; 71:1313-24. https://doi.org/10.1158/0008-5472.CAN-10-1031.

83. Aakula A, Leivonen SK, Hintsanen P, Aittokallio T, Ceder Y, Børresen-Dale AL, Perälä M, Östling P, Kallioniemi O. MicroRNA-135b regulates ER $\alpha, \mathrm{AR}$ and HIF1AN and affects breast and prostate cancer cell growth. Mol Oncol. 2015; 9:1287-300. https://doi.org/10.1016/j.molonc.2015.03.001.

84. Väremo L, Nielsen J, Nookaew I. Enriching the gene set analysis of genome-wide data by incorporating directionality of gene expression and combining statistical hypotheses and methods. Nucleic Acids Res. 2013; 41:4378-91. https://doi.org/10.1093/nar/gkt111.

85. Dweep H, Sticht C, Pandey P, Gretz N. miRWalk database: prediction of possible miRNA binding sites by "walking" the genes of three genomes. J Biomed Inform. 2011; 44:839-47. https://doi.org/10.1016/j.jbi.2011.05.002.

86. Krek A, Grün D, Poy MN, Wolf R, Rosenberg L, Epstein EJ, MacMenamin P, da Piedade I, Gunsalus KC, Stoffel M, Rajewsky N. Combinatorial microRNA target predictions. Nat Genet. 2005; 37:495-500. https://doi.org/10.1038/ng1536.

87. Kertesz M, Iovino N, Unnerstall U, Gaul U, Segal E. The role of site accessibility in microRNA target recognition. Nat Genet. 2007; 39:1278-84. https://doi.org/10.1038/ng2135.

88. Miranda KC, Huynh T, Tay Y, Ang YS, Tam WL, Thomson AM, Lim B, Rigoutsos I. A pattern-based method for the identification of MicroRNA binding sites and their corresponding heteroduplexes. Cell. 2006; 126:1203-17. https://doi.org/10.1016/j.cell.2006.07.031.

89. Agarwal V, Bell GW, Nam JW, Bartel DP. Predicting effective microRNA target sites in mammalian mRNAs. Elife. 2015; 4. https://doi.org/10.7554/eLife.05005.

90. Vejnar CE, Zdobnov EM. miRmap: comprehensive prediction of microRNA target repression strength. Nucleic Acids Res. 2012; 40:11673-83. https://doi.org/10.1093/nar/gks901.

91. Enright AJ, John B, Gaul U, Tuschl T, Sander C, Marks DS. MicroRNA targets in Drosophila. genome biol. BioMed Central; 2003; 5:R1. https://doi.org/10.1186/gb-2003-5-1-r1.

92. Hothorn T, Bretz F, Westfall P. Simultaneous inference in general parametric models. Biom J. 2008; 50:346-63. https://doi.org/10.1002/bimj.200810425. 